Full Length Article

\title{
Distinct immunopathology in the early stages between different antiresorptives-related osteonecrosis of the jaw-like lesions in mice
}

\author{
Hiroki Hayano $^{\mathrm{a}, 1}$, Shinichiro Kuroshima ${ }^{\mathrm{a}, *, 1}$, Muneteru Sasaki ${ }^{\mathrm{a}}$, Saki Tamaki ${ }^{\mathrm{a}}$, Maaya Inoue ${ }^{\mathrm{a}}$,

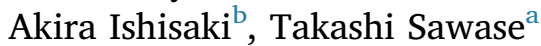 \\ a Department of Applied Prosthodontics, Graduate School of Biomedical Sciences, Nagasaki University, Nagasaki 852-8588, Japan \\ ${ }^{\mathrm{b}}$ Division of Cellular Biosignal Sciences, Department of Biochemistry, Iwate Medical University, Shiwa-gun, Iwate 028-3694, Japan
}

A R T I C L E I N F O

\section{Keywords:}

Osteonecrosis of the jaw

Denosumab

Bisphosphonates

Tooth extraction

Wound healing

Macrophages

\begin{abstract}
A B S T R A C T
There is limited information about denosumab-related osteonecrosis of the jaw (DRONJ), unlike bisphosphonate-related ONJ (BRONJ). The mode of action is clearly different between denosumab and bisphosphonates. DRONJ occurs mainly following tooth extraction in cancer patients treated with the combination of denosumab and other drugs including chemotherapy. However, DRONJ animal models similar to these clinical situations have not been developed. The aims of this study were to 1) create a new model of high-prevalence chemotherapy/anti-RANKL antibody-related ONJ-like lesions to mimic patients receiving a denosumab/chemotherapy combination; and 2) compare the histopathological and immunopathological findings in the early stages of BRONJ-like and anti-RANKL antibody-related ONJ-like lesions. Cyclophosphamide (CY) and antimouse RANKL monoclonal antibody $(\mathrm{mAb})$ or zoledronate combination therapy $(\mathrm{CY} / \mathrm{mAb}$ and $\mathrm{CY} / \mathrm{ZA}$, respectively) was performed to create ONJ-like lesions in female C57BL/6J mice. Both maxillary first molars were extracted at 3 weeks after drug administration. The animals were euthanized at either 2 or 4 weeks after tooth extraction. Increased necrotic bone and empty lacunae with decreased living bone and osteocyte numbers were common histopathological findings in $\mathrm{CY} / \mathrm{mAb}$ - and $\mathrm{CY} / \mathrm{ZA}$-induced impaired wound healing at 4 weeks after tooth extraction, and they were diagnosed as ONJ-like lesions based on validation of BRONJ and DRONJ in humans. In areas of impaired healing at 2 weeks post-extraction, decreases in angiogenesis and F4/80 ${ }^{+} \mathrm{LYVE}^{-} \mathrm{1}^{-}$ macrophages were noted as common immunopathological findings, although anti-angiogenesis was worse with $\mathrm{CY} / \mathrm{mAb}$ than with $\mathrm{CY} / \mathrm{ZA}$. Interestingly, $\mathrm{CY} / \mathrm{mAb}$ did not reduce $\mathrm{F} 4 / 80^{+} \mathrm{LYVE}-1^{+}$cells and normal lymphangiogenesis remained, whereas CY/ZA profoundly suppressed the larger size of $\mathrm{F} 4 / 80^{+} \mathrm{LYVE}-1^{+}$cells, similar to vessels with a concomitant decrease in lymphangiogenesis. Therefore, the distribution of the larger size of F4/80 ${ }^{+}$LYVE- ${ }^{+}$cells differed in the early stages between different antiresorptive-induced ONJ-like lesions in conjunction with lymphangiogenesis, although the histopathological findings were similar. These findings suggest that the pathogenesis of BRONJ and DRONJ may differ due to the distributions of F4/80 ${ }^{+} \mathrm{LYVE}-1^{+}$tubelike-structured cells.
\end{abstract}

\section{Introduction}

Denosumab, which is a fully human monoclonal antibody to RANKL, has been widely used for osteoporotic and cancer patients. Denosumab has recently replaced zoledronate for cancer patients receiving chemotherapies including cyclophosphamide (CY). The effectiveness of denosumab has been demonstrated to be comparable to that of zoledronate with respect to the reduction of skeletal-related events in cancer patients [1-4]. However, denosumab-related ONJ (DRONJ) was first reported in 2010 [5]. In contrast, bisphosphonates, which are categorized as antiresorptive drugs similar to denosumab, were initially reported in 2003 to induce bisphosphonate-related ONJ (BRONJ) [6]. The exact pathogenetic mechanisms of DRONJ and BRONJ are unclear. In particular, the details of the histopathology and immunopathology of DRONJ remain largely unknown.

Bisphosphonates, which have more than a 10-year half-life, are categorized as chemical reagents that induce osteoclast apoptosis and block function via the inhibition of the mevalonate pathway [7]. On the

* Corresponding author at: Department of Applied Prosthodontics, Graduate School of Biomedical Sciences, Nagasaki University, 1-7-1, Sakamoto, Nagasaki 8528588, Japan.

E-mail address: kuroshima@nagasaki-u.ac.jp (S. Kuroshima).

${ }^{1} \mathrm{H}$ Hayano and S Kuroshima contributed equally to this work. 


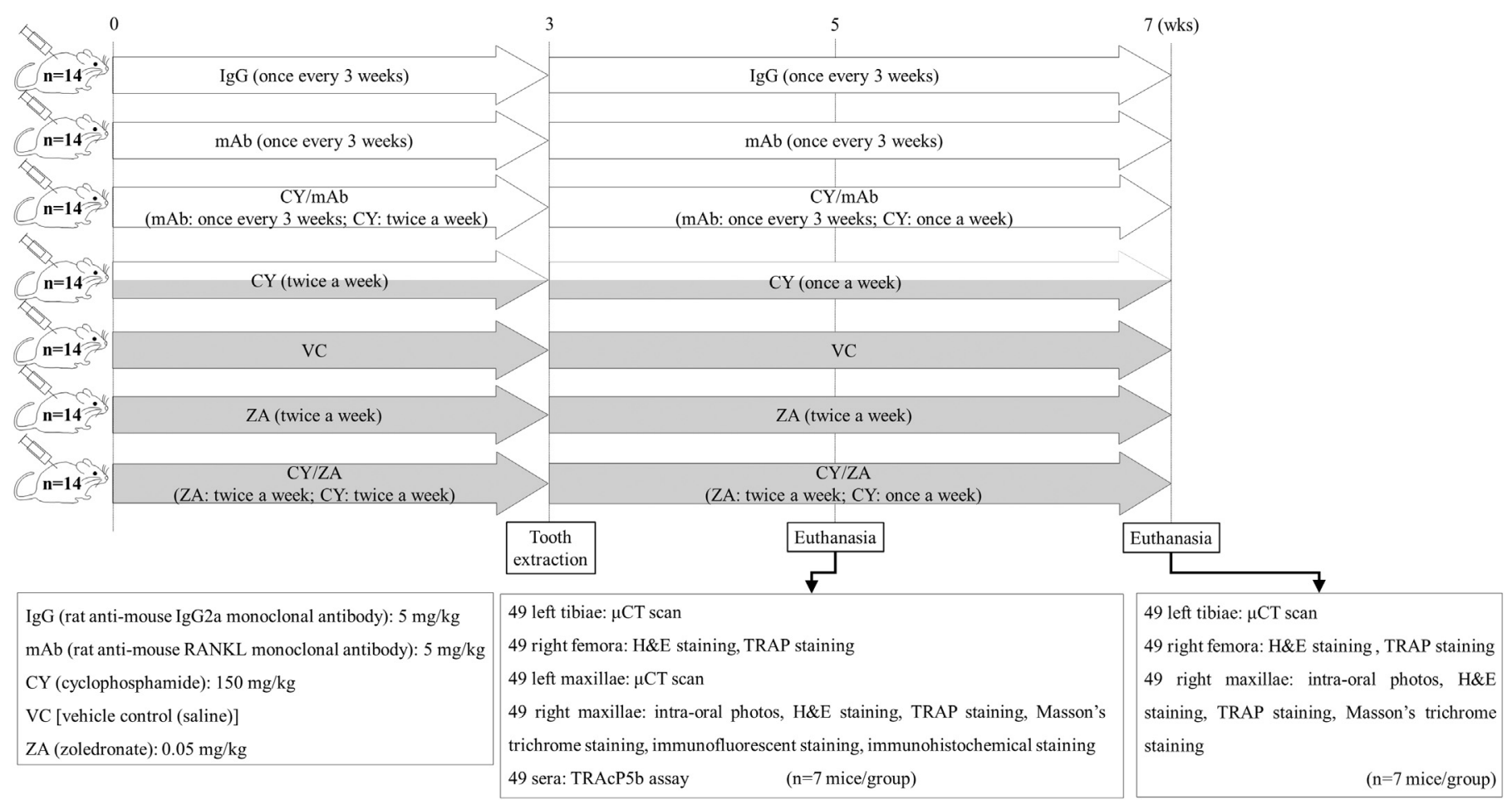

Fig. 1. Experimental schedule. Drugs were administered for 5 and 7 weeks. Both maxillary first molars were extracted at 3 weeks after drug treatment. All mice were euthanized at either 2- or 4-weeks post-extraction.

other hand, denosumab, which has only a 26-day half-life, is a proteinbased drug that negatively affects osteoclast formation, function, and survival [8]. Namely, the mode of action of denosumab is quite different from that of bisphosphonates, although both antiresorptive drugs increase bone mass and bone mineral density (BMD).

We recently developed a high-prevalence BRONJ model using female C57BL/6J mice with zoledronate/chemotherapy combination therapy to mimic clinical situations [9], since BRONJ occurs mainly in patients receiving bisphosphonate/chemotherapeutic combination therapy [10]. On the other hand, creation of a useful DRONJ animal model has been challenging, since denosumab does not bind to rodent RANKL, though some studies have reported establishment of DRONJlike lesions in rodents using osteoprotegerin-Fc (OPG-FC), RANK-Fc, and anti-RANKL monoclonal antibody [11-14]. However, their regimens were antibody monotherapies that rarely induce DRONJ in osteoporosis patients [15], although DRONJ occurred mainly in patients receiving combination therapy consisting of denosumab and other drugs, including chemotherapy [16]. Therefore, development of a new DRONJ model that mimics such clinical situations with a high risk of DRONJ is needed to explore the pathoetiology of and establish the treatment strategy for DRONJ.

Immune cells such as neutrophils, polymorphonuclear leukocytes, macrophages, and dendritic cells play a pivotal role in wound healing processes to eliminate invading bacteria and promote immune reactions. In particular, some studies have reported that macrophages may be associated with developing BRONJ in animal and clinical studies $[17,18]$, although whether macrophages are correlated with developing DRONJ remains unclear. Recently, $\mathrm{F} 4 / 80^{+} \mathrm{CD} 11 \mathrm{~b}^{+}$and $\mathrm{CD} 11 \mathrm{~b}^{+}$ macrophages expressing lymphatic vessel endothelial hyaluronan receptor $1^{+}$(LYVE-1), which has been identified as one of the lymphatic endothelial markers, have been reported to be linked with inflammation and to be able to transdifferentiate into lymphatic endothelial cells $[19,20]$. Blood and lymphatic vessels are required for immune cell migration into injured tissues and lymph nodes, respectively [21,22]. However, few scientific data on macrophages, angiogenesis, and lymphangiogenesis in DRONJ are available in humans and rodents, although several studies have reported them in BRONJ.

Therefore, we hypothesized that the immunopathological findings, such as macrophages, angiogenesis, and lymphangiogenesis, differ between DRONJ and BRONJ from the early stages of their development, based on the scientific rationale of the different modes of action of denosumab and bisphosphonates. We thought that this hypothesis would be explored by comparing an already created high-prevalence BRONJ model [9] with a new DRONJ model with CY/anti-RANKL antibody combination therapy.

The aims of this study were: 1) to develop a new model of highprevalence CY/anti-RANKL antibody combination therapy-induced ONJ-like lesions that mimic clinical situations at high risk of DRONJ; and 2) to compare the pathological and immunopathological findings based on macrophages, lymphangiogenesis, and angiogenesis in the early stages of BRONJ- and anti-RANKL antibody-related ONJ-like lesions in mice.

\section{Materials and methods}

\subsection{Development of high-prevalence ONJ-like lesions by anti-mouse $R A N K L$ neutralizing antibody in mice}

All animal experiments were performed according to the ARRIVE Guidelines (https://www.nc3rs.org.uk/arrive-guidelines). A total of 106 8-week-old female C57BL/6J mice were used. Rat anti-mouse RANKL monoclonal antibody (mAb; Oriental Yeast Co., Ltd., Tokyo, Japan), bisphosphonate (Zometa, ZA; Novartis, Stein, Switzerland), cyclophosphamide (CY, C3797; Sigma-Aldrich, St. Louis, MO, USA), and rat anti-mouse IgG2a monoclonal antibody (IgG; BE0089; Bio X Cell, West Lebanon, NH, USA) were purchased [23,24,25]. To create high-prevalence BRONJ-like lesions, drug therapy was performed with tooth extraction, as previously described [9,25]. Briefly, subcutaneous ZA and intraperitoneal CY were administered for 5 and 7 weeks (CY) ZA, ZA; $0.05 \mathrm{mg} / \mathrm{kg}$ twice a week, CY: $150 \mathrm{mg} / \mathrm{kg}$ twice and once a week before and after tooth extraction, respectively). Both maxillary first molars were extracted 3 weeks after drug administration. The 
animals were euthanized at either 2 or 4 weeks post-extraction ( $n=7$ mice/group). Next, to develop high-prevalence mAb-related ONJ (mAb$\mathrm{ONJ}$ ) -like lesions, subcutaneous $\mathrm{mAb}$ and intraperitoneal $\mathrm{CY}$ combination therapy $(\mathrm{CY} / \mathrm{mAb})$ was performed with tooth extraction (mAb: $5 \mathrm{mg} / \mathrm{kg}$ once every 3 weeks) by referring to the above-mentioned protocol $[9,25]$. CY, ZA, and mAb monotherapies were also performed with the same dosages of each used in combination therapy. Saline and IgG (5 mg/kg once every 3 weeks) were used as controls for ZA- and mAb-treated groups, respectively ( $n=7 \mathrm{mice} /$ group) (Fig. 1). Mice were euthanized at 2 and 4 weeks after tooth extraction. Maxillae, tibiae, femora, and sera were collected. Eight mice with root fractures when tooth extraction was performed were excluded from this study. Animal care and experimental procedures were performed in accordance with the Guidelines for Animal Experimentation of Nagasaki University, with approval from the Ethics Committee for Animal Research.

\subsection{Microcomputed tomography $(\mu C T)$ assessment}

Fixation was performed with $10 \%$ neutral buffered formalin following the dissection of 49 left maxillae at 2 weeks post-extraction, and 98 left tibiae at 2 and 4 weeks post-extraction ( $n=7$ each/group). The regions of interests (ROIs) of tooth extraction sockets were set as the total sockets of the mesial root and two distal roots including the outer bone wall from the alveolar ridge to the root apex. The ROIs of tibiae ranged from 200 to $2200 \mu \mathrm{m}$ below the growth plates of proximal metaphysis. Samples were analyzed using TRI/3D-Bon (Ratoc System Engineering, Tokyo, Japan). Bone volume fraction (BV/TV) of long bones or bone mass (BV/TV) of tooth extraction sockets, trabecular number (Tb.N), trabecular thickness (Tb.Th), trabecular separation (Tb.Sp), and BMD were assessed with the direct-measure technique according to guidelines for $\mu \mathrm{CT}$ analyses [26].

\subsection{Hematoxylin and eosin (H\&E), tartrate-resistant acid phosphatase (TRAP) and Masson's trichrome staining}

Tissue staining was performed as previously described [9]. Briefly, 5 - $\mu \mathrm{m}$-thick-paraffin sections of 98 right maxillae and 98 right femora at 2 and 4 weeks post-extraction were used. H\&E staining was performed according to the manufacturer's instructions to histomorphometrically evaluate wound healing of tooth extraction sockets and the bone area of femora. TRAP staining was carried out to detect osteoclasts on bone surface (386A, Sigma-Aldrich). Masson's trichrome staining (HT15, Sigma-Aldrich) was conducted to visualize collagen fibers and polymorphonuclear leukocytes (PMNs) in the tooth extraction sockets.

\subsection{Immunofluorescent and immunohistochemical staining}

LYVE- $1^{+}$lymphatics, CD31 ${ }^{+}$blood vessels, F4/80 ${ }^{+}$LYVE- $1^{-}$macrophages and $\mathrm{F} 4 / 80^{+} \mathrm{LYVE}-1^{+}$cells were examined in the connective tissue of tooth extraction sockets in 49 right maxillae at 2 weeks postextraction. Sections were fixed, rehydrated, subjected to antigen retrieval and blocking, and then incubated with primary antibodies at $4{ }^{\circ} \mathrm{C}$ for $12 \mathrm{~h}$. A cocktail of rabbit anti-mouse LYVE-1 polyclonal antibody (ab14917; Abcam, Cambridge, MA, USA) at 1:100 dilution and rat anti-mouse CD31 monoclonal antibody (ab56299; Abcam) at 1:100 dilution was used to visualize lymphatic and blood vessels. A cocktail of rat anti-mouse F4/80 monoclonal antibody (ab16911; Abcam) at 1:50 dilution and rabbit anti-mouse LYVE-1 polyclonal antibody (ab14917; Abcam) at 1:100 dilution was used to detect F4/80 ${ }^{+} \mathrm{LYVE}^{-}{ }^{-}$macrophages and $\mathrm{F} 4 / 80^{+} \mathrm{LYVE}-1^{+}$cells in soft tissue. Antibody-incubated sections were further reacted with specific secondary antibodies to each primary antibody at room temperature for $1 \mathrm{~h}$. A cocktail of Alexa Fluor 488 goat anti-rabbit IgG and Alexa Fluor 546 goat anti-rat IgG (Invitrogen, Carlsbad, CA, USA) was used at 1:200 dilution to react with the cocktail of primary antibodies. Then, primary and secondary antibody-treated sections were mounted with VECTASHIELD Antifade Mounting Medium with DAPI (H-1200; Vector Laboratories, Burlingame, CA, USA).

For immunohistochemistry for VEGFA, sections were incubated at $4{ }^{\circ} \mathrm{C}$ overnight with a rabbit anti-mouse VEGFA polyclonal antibody (ab46154; Abcam) at 1:200 dilution. The sections were then incubated with $0.3 \%$ hydrogen peroxidase for $10 \mathrm{~min}$ to remove endogenous peroxidase activity. Goat anti-rabbit IgG conjugated with horseradish peroxidase (HRP) was used as the secondary antibody at 1:1000 dilution (ab6721; Abcam). Proteins were developed with 3,3-diaminobenzidine (DAB Substrate Kit: ab64238; Abcam) and then counterstained with hematoxylin and mounted.

H\&E-, TRAP-, and Masson's trichrome-stained sections and immunofluorescent and immunohistochemical stained-sections were photomicrographed with light or fluorescent microscopy (Axio Scope A1; Zeiss, Oberkochen, Germany). Images were histomorphometrically analyzed with ZEN2 (Zeiss) and ImageJ software [version 1.47; National Institutes of Health (NIH), Bethesda, MD, USA; https://imagej. nih.gov/ij/index.html].

\subsection{Evaluation of wound healing and diagnosis of ONJ-like lesions in mice}

To diagnose persistent exposed bone without epithelial coverage in tooth extraction sockets as mAb-ONJ-like lesions in mice, histological findings and gross validation methods of human BRONJ were used as previously reported [27-30]. In humans, 8 weeks are required to diagnose persistent open wounds as BRONJ and DRONJ. On the other hand, the duration of tooth extraction socket healing in mice takes approximately 2 weeks, which indicates that the diagnostic timing of ONJ-like lesions is earlier than that of DRONJ/BRONJ in humans [31]. In the present study, as in our previous studies $[9,32]$, sustained open wounds with exposed bone for 4 weeks after tooth extraction were diagnosed as mAb-ONJ- or BRONJ-like lesions. Moreover, pathological and immunopathological evaluations were conducted at 2 weeks postextraction, since important molecular events related to tooth extraction socket healing occur within 2 weeks in mice [31,33]. Therefore, to evaluate tooth extraction socket healing, quantitative analyses were performed using the following bone parameters as previously described [9,25]: 1) number of tooth extraction sockets with open wounds using intra-oral photographs [prevalence of open wounds (\%)]; 2) actual surface of exposed bone without epithelial coverage [wound open area $\left.\left(\mathrm{mm}^{2}\right)\right]$; 3) the bone area with morphologically normal osteocytes [living bone (\%)]; 4) number of osteocytes [osteocyte density $\left.\left.\left(\# / \mathrm{mm}^{2}\right)\right] ; 5\right)$ the devital bone area in which there were $\geq 10$ adjacent empty or pyknotic osteocyte lacunae [necrotic bone (\%)] [34,35] and the number of empty osteocyte lacunae [empty lacunae $\left.\left.\left(\# / \mathrm{mm}^{2}\right)\right] ; 6\right)$ osteoclast perimeter [N.Oc/BS (\#/mm)] and; 7) number of PMNs within $100 \mu \mathrm{m}$ of the bone surfaces of extraction sockets under higher magnifications [PMN infiltration $\left.\left(\# / \mathrm{mm}^{2}\right)\right]$. Impaired wound healing at 4 weeks post-extraction was diagnosed as mAb-ONJ- and BRONJ-like lesions based on the above-mentioned items 1) to 5). All of the above parameters were used to evaluate tooth extraction socket healing at 2 weeks after extraction.

\subsection{Immunopathological assessment of impaired wound healing at 2 weeks after tooth extraction}

The following parameters were further analyzed to assess soft tissue healing: number of blood and lymphatic vessels $\left[\mathrm{CD} 31^{+}\left(\# / \mathrm{mm}^{2}\right)\right.$ and LYVE1 ${ }^{+}$vessels $\left(\# / \mathrm{mm}^{2}\right)$, respectively]; surface area of blood and lymphatic vessels [Blood and Lymphatic vessel density (\%), respectively]; VEGFA-positive cells [VEGFA $\left(\# / \mathrm{mm}^{2}\right)$ ]; F4/80-positive and LYVE-1-negative cells $\left[\mathrm{F} 4 / 80^{+} \mathrm{LYVE}^{-}{ }^{-}\right.$macrophages $\left.\left(\# / \mathrm{mm}^{2}\right)\right]$; F4/ 80 and LYVE-1 double-positive cells with long axis length $>20 \mu \mathrm{m}$ (tube-like structures) $\left[\mathrm{F} 4 / 80^{+} \mathrm{LYVE}^{+}\right.$cells $\left.>20 \mu \mathrm{m}\left(\# / \mathrm{mm}^{2}\right)\right]$; and F4/80 and LYVE-1 double-positive cells with long axis length $\leq 20 \mu \mathrm{m}$ 
(like F4/80 ${ }^{+}$LYVE- $1^{-}$macrophages) $\left[\mathrm{F} 4 / 80^{+}\right.$LYVE- $^{+}$cells $\leq 20 \mu \mathrm{m}$ $\left.\left(\# / \mathrm{mm}^{2}\right)\right]$ in the connective tissue near the extraction sockets. Three serial sections per mouse were averaged and scored in all histomorphometric and immunohistochemical analyses by two independent evaluators (HH and SK).

\subsection{ELISA for serum TRAP isoform $5 b$ (TRAcP5b)}

Serum TRAcP5b levels at 2 weeks post-extraction were measured to investigate the effects of the administered drugs on systemic osteoclasts ( $n=7$ samples/each group). Blood was collected by cardiac puncture at 2 weeks, immediately after euthanasia. Serum samples were prepared by centrifugation and kept at $-80{ }^{\circ} \mathrm{C}$ before use. ELISA was carried out to measure serum TRAcP5b levels using the MouseTRAP ${ }^{\mathrm{TM}}$ Assay (TRAcP 5b ELISA) (DS-SBTR103; Immunodiagnostic Systems Ltd., Boldon, Tyne and Wear, UK). Measurement was performed at an absorbance of $405 \mathrm{~nm}$ using a microplate reader (MultiSkan FC Advance, Thermo Scientific, Waltham, MA, USA). Mean values of duplicated samples were used as measurement data.

\subsection{Comparison of drug effects between $C Y / m A b$ and $C Y / Z A$ combination therapies}

Drug effects were assessed to investigate which combination therapy affects living bone, osteocyte density, necrotic bone, empty lacunae, N.Oc/BS, PMN infiltration, blood vessels, blood vessel density, VEGFA, lymphatic vessels, lymphatic vessel density, F4/80 ${ }^{+}$LYVE1 $^{-}$ macrophages, F4 $/ 80^{+} \mathrm{LYVE}^{+}$cells $>20 \mu \mathrm{m}$ and $\mathrm{F} 4 / 80^{+} \mathrm{LYVE}^{+}{ }^{+}$ cells $\leq 20 \mu \mathrm{m}$. Drug effects for these evaluation parameters were defined based on the adjusted ratios of the numerical average differences of analyzed data for $\mathrm{CY} / \mathrm{ZA}$ or $\mathrm{CY} / \mathrm{mAb}$ combination therapy to the analyzed data of each control.

\subsection{Statistical analyses}

The Shapiro-Wilk test was used to test for normality. One-way ANOVA and the Kruskal-Wallis test were used for parametric and nonparametric data, respectively. All statistical analyses were conducted using Systat 13.2 (Systat Software, Chicago, IL, USA). All data are presented as means \pm SEM. A $p$-value $<0.05$ was deemed significant. In comparisons between two groups, Student's $t$-test and the Mann-Whitney $U$ test were used for parametric and nonparametric data, respectively.

\section{Results}

\subsection{High-prevalence open wounds induced by antiresorptive/ chemotherapeutic combination therapies but not antiresorptive monotherapies}

Before tooth extraction, no wounds were confirmed in the oral cavity (Fig. 2A). Exposed bone was commonly observed in both CY/ $\mathrm{mAb}$ and CY/ZA [13 of 14 sockets (both 92.8\%)] and CY [7 of 14 sockets (50\%)], although no open wounds were noted in controls and $\mathrm{mAb}$ or ZA [0 of 14 sockets] (Fig. 2B). Wound open areas were significantly larger in both $\mathrm{CY} / \mathrm{mAb}$ and $\mathrm{CY} / \mathrm{ZA}$ than in controls, $\mathrm{CY}$ and $\mathrm{mAb}$ or ZA (Fig. 2C). Both $\mathrm{mAb}$ and ZA therapy also severely suppressed osteoclasts on bone surfaces of tooth extraction sockets and serum TRAcP5b levels when compared with each control, irrespective of CY (Fig. 2D-F).

At 4 weeks post-extraction, $85.7 \%$ and $78.6 \%$ of tooth extraction sockets in $\mathrm{CY} / \mathrm{mAb}$ and $\mathrm{CY} / \mathrm{ZA}$ were not healed with open wounds [12 of 14 sockets, 11 of 14 sockets, respectively], although CY was grossly healed (Sup. Fig. 1A and B). Both combination therapies significantly increased wound open areas when compared with those in controls, CY and mAb or ZA (Sup. Fig. 1C). Moreover, both combination therapies and CY monotherapy significantly decreased living bone and osteocyte density with increased necrotic bone and the number of empty lacunae when compared with those in controls and mAb or ZA (Sup. Fig. 1D-H). Importantly, CY monotherapy significantly reduced necrotic bone when compared with that in both combination therapies (Sup. Fig. 1G). Therefore, impaired healing of soft and hard tissue of tooth extraction sockets induced by $\mathrm{CY} / \mathrm{mAb}$ and $\mathrm{CY} / \mathrm{ZA}$ at 4 weeks post-extraction was defined/diagnosed as mAb-ONJ- and BRONJ-like lesions, respectively. Wound healing induced by CY monotherapy was not defined as ONJlike lesions, since normal soft tissue completely covered tooth extraction sockets, and there was less necrotic bone.

\subsection{Impaired osseous and soft tissue healing of tooth extraction sockets induced by $C Y / m A b$ and $C Y / Z A$ at 2 weeks post-extraction}

In sagittal H\&E-stained images, no bone fill with more necrotic bone was noted in both $\mathrm{CY} / \mathrm{mAb}$ and $\mathrm{CY} / \mathrm{ZA}$ (Fig. 3A). Both $\mathrm{CY} / \mathrm{mAb}$ and $\mathrm{CY} / \mathrm{ZA}$ significantly decreased living bone in tooth extraction sockets with decreased normal osteocytes (Fig. 3B and C). In conjunction with decreased living bone, these combination therapies significantly increased the amount of necrotic bone with an increased number of empty or pyknotic osteocyte lacunae (Fig. 3D and E). However, mAb and ZA did not affect living bone and osteocyte density, although both monotherapies tended to slightly increase necrotic bone with empty lacunae (Fig. 3D and E). On the other hand, CY monotherapy increased necrotic bone and empty lacunae without affecting living bone, although the amounts of necrotic bone and empty lacunae were obviously smaller in CY monotherapy than in both combination therapies (Fig. 3D and E).

Moreover, on $\mu \mathrm{CT}, \mathrm{mAb}$ and ZA significantly increased bone fill of tooth extraction sockets with increased Tb.Th and decreased Tb.Sp compared with controls. Both combination therapies and CY monotherapy significantly decreased bone fill of tooth extraction sockets with decreased Tb.Th and Tb.N and increased Tb.Sp when compared with those in controls, although both combination therapies significantly decreased $\mathrm{Tb}$.Th and Tb.Sp compared with CY monotherapy. CY therapy significantly suppressed the antiresorptive effects on alveolar bone induced by $\mathrm{mAb}$ and $\mathrm{ZA}$ (Sup. Fig. $2 \mathrm{~A}-\mathrm{E}$ ). $\mathrm{CY} / \mathrm{mAb}$ and $\mathrm{CY} /$ ZA significantly increased BMD in the tooth extraction sockets compared with controls (Sup. Fig. 2F).

On trichrome stained-images, tooth extraction sockets appeared to be filled with PMNs in both $\mathrm{CY} / \mathrm{mAb}$ and $\mathrm{CY} / \mathrm{ZA}$, whereas fewer PMNs seemed to be found in controls, $\mathrm{CY}$ and $\mathrm{mAb}$ or ZA (Fig. 3F). Indeed, both $\mathrm{CY} / \mathrm{mAb}$ and $\mathrm{CY} / \mathrm{ZA}$ significantly decreased collagen production and increased infiltration of PMNs compared with controls, $\mathrm{CY}$ and $\mathrm{mAb}$ or ZA (Fig. $3 \mathrm{G}$ and $\mathrm{H}$ ).

\subsection{Effects of administered drugs on angiogenesis in soft tissue wounds}

In this study, angiogenesis and VEGFA distribution were immunohistochemically investigated to determine whether blood vessel formation would be inhibited by mAb monotherapy and/or $\mathrm{CY} / \mathrm{mAb}$ combination therapy. As described in our previous study [32], CY/ZA combination therapy and $\mathrm{CY}$ monotherapy, but not ZA monotherapy, severely inhibited vasculogenesis in the connective tissue of tooth extraction sockets. Interestingly, mAb administration had an anti-angiogenic effect on the connective tissue, regardless of $\mathrm{CY}$ administration. Moreover, anti-angiogenesis effects were greater with $\mathrm{CY} / \mathrm{mAb}$ combination therapy than with by $\mathrm{mAb}$ and $\mathrm{CY}$ monotherapies (Fig. 4A, C, D).

$\mathrm{CY} / \mathrm{mAb}, \mathrm{mAb}$, and $\mathrm{CY}$ significantly decreased VEGFA distribution compared with controls, although the effect was greater with $\mathrm{CY} / \mathrm{mAb}$ than with $\mathrm{mAb}$ and $\mathrm{CY}$. CY/ZA, ZA, and CY also significantly decreased VEGFA distribution compared with controls (Fig. 4B and E). 

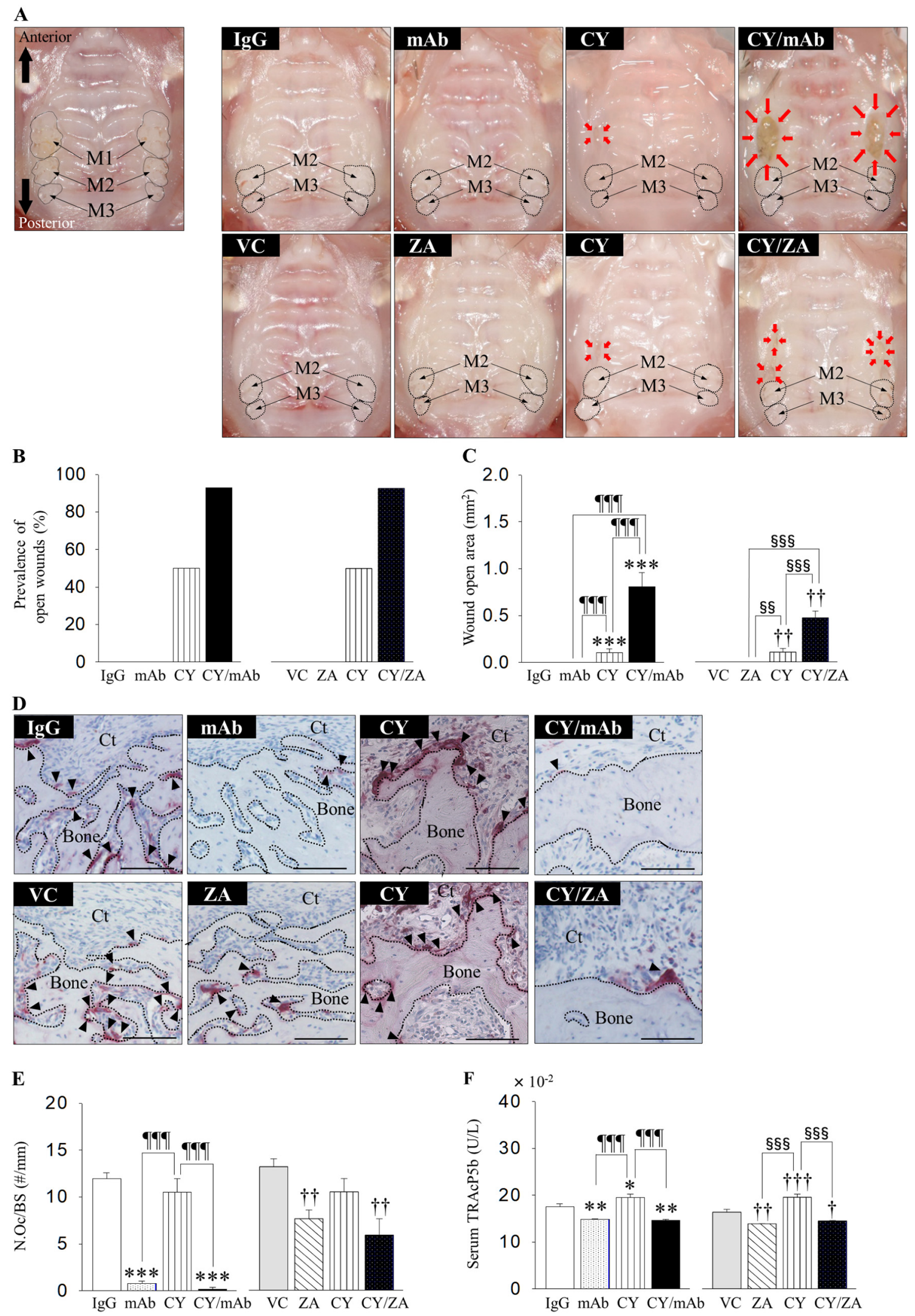

(caption on next page) 


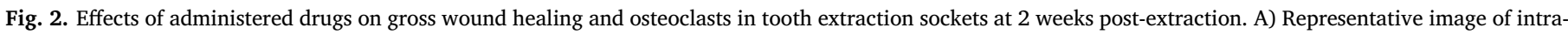

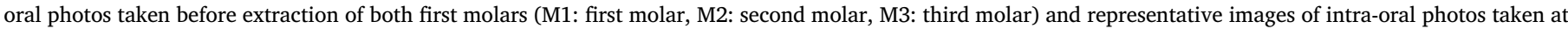

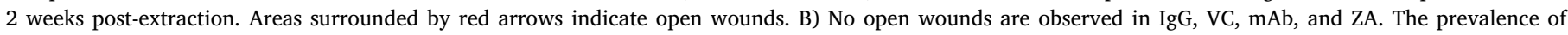

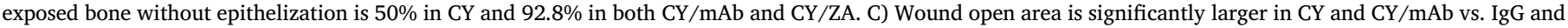

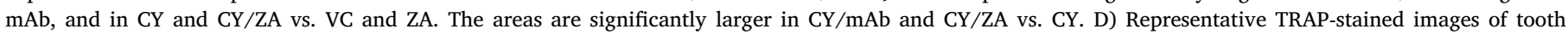

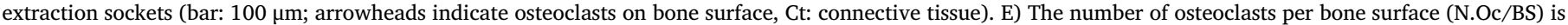

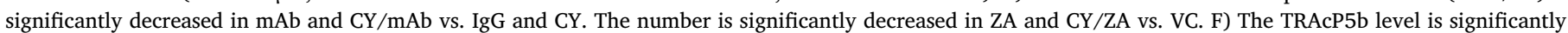

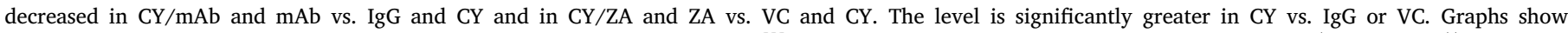

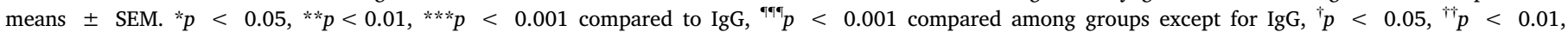

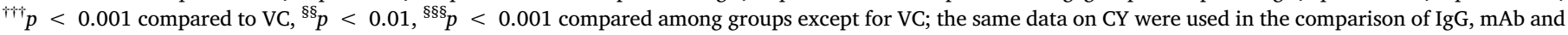
$\mathrm{CY} / \mathrm{mAb}$, and VC, ZA and ZA/CY; $n=7$ mice/group.

\subsection{Effects of administered drugs on lymphangiogenesis in soft tissue wounds}

Moreover, to investigate the effects of the administered drugs on lymphangiogenesis in the connective tissue of tooth extraction sockets, the number of lymphatics was evaluated. No effects of $\mathrm{mAb}$ and $\mathrm{CY}$ monotherapy on lymphangiogenesis were noted. Interestingly, normal lymphangiogenesis was observed in the connective tissue of tooth extraction sockets affected by $\mathrm{CY} / \mathrm{mAb}$, whereas more severely suppressed lymphangiogenesis with decreased vessel density occurred in the connective tissue affected by CY/ZA (Fig. 4A, F and G).

\subsection{Different distribution of $\mathrm{F} 4 / 80^{+} \mathrm{LYVE}-1^{+}$cells $>20 \mu \mathrm{m}$ in soft tissue wounds between $C Y / m A b$ and $C Y / Z A$ combination therapies}

F4 $/ 80^{+}$LYVE- $^{-}$macrophages, $\mathrm{F} 4 / 80^{+} \mathrm{LYVE}^{-} 1^{+}$cells $>20 \mu \mathrm{m}$ and F4/80 ${ }^{+}$LYVE$^{+} 1^{+}$cells $\leq 20 \mu \mathrm{m}$ in the connective tissue of tooth extraction sockets were investigated immunohistochemically (Fig. 5A). No effects of $\mathrm{mAb}$ and $\mathrm{CY}$ monotherapy on $\mathrm{F} 4 / 80^{+} \mathrm{LYVE}-1^{-}$macrophages were observed, although $\mathrm{CY} / \mathrm{mAb}$ significantly reduced macrophage numbers in soft tissue wounds compared with all comparison groups (Fig. 5B). However, mAb did not affect the number of F4/ $80^{+} \mathrm{LYVE}^{-} 1^{+}$cells, irrespective of $\mathrm{CY}$ administration and cell size (Fig. 5C). Conversely, both CY/ZA and ZA significantly decreased F4/ $80^{+}$LYVE- $1^{-}$macrophage numbers in the connective tissue of tooth extraction sockets (Fig. 5B). Moreover, CY/ZA significantly reduced the number of F4/80 ${ }^{+} \mathrm{LYVE}^{+}{ }^{+}$cells $>20 \mu \mathrm{m}$, but not $\mathrm{F} 4 / 80^{+} \mathrm{LYVE}-1^{+}$ cells $\leq 20 \mu \mathrm{m}$ compared with controls (Fig. 5C).

\subsection{Similar histopathological but distinct immunopathological findings between different antiresorptive-induced ONJ-like lesions}

Finally, the effects of $\mathrm{CY} / \mathrm{mAb}$ and $\mathrm{CY} / \mathrm{ZA}$ on assessment parameters of hard and soft tissue wound healing were compared. Drug effects based on histopathological parameters were generally similar between $\mathrm{CY} / \mathrm{mAb}$ and $\mathrm{CY} / \mathrm{ZA}$ except for N.Oc/BS and empty osteocyte lacunae (Fig. 6A-F). On the other hand, drug effects based on immunopathological findings were quite different between the antiresorptives. Drug effects on angiogenesis-related parameters were significantly greater in $\mathrm{CY} / \mathrm{mAb}$ than in $\mathrm{CY} / \mathrm{ZA}$ (Fig. 6G-I). On the other hand, drug effects on lymphangiogenesis-related parameters were significantly smaller in $\mathrm{CY} / \mathrm{mAb}$ than in $\mathrm{CY} / \mathrm{ZA}$ (Fig. 6J and K). Moreover, drug effects on $\mathrm{F} 4 / 80^{+} \mathrm{LYVE}-1^{+}$cells $>20 \mu \mathrm{m}$ were significantly smaller in $\mathrm{CY} / \mathrm{mAb}$ than in $\mathrm{CY} / \mathrm{ZA}$, although the effects on F4/ $80^{+}$LYVE- $1^{-}$macrophages and F4/80 ${ }^{+}$LYVE- $1^{+}$cells $\leq 20 \mu \mathrm{m}$ were the same between $\mathrm{CY} / \mathrm{mAb}$ and $\mathrm{CY} / \mathrm{ZA}($ Fig. $6 \mathrm{~L}-\mathrm{N}$ ).

\section{Discussion}

In 2011, anti-RANKL neutralizing antibody, which has a similar therapeutic effect to denosumab, was developed [36]. A single $5 \mathrm{mg} / \mathrm{kg}$ injection of this antibody has been demonstrated to increase BMD with suppressed N.Oc/BS in long bones at 14 days post-administration. It has also been reported that the neutralization effect of RANKL persists for
4 weeks after one injection of this antibody [36]. Moreover, another recent study has indicated that subcutaneous injections of the developed $\mathrm{mAb}$ at $5 \mathrm{mg} / \mathrm{kg}$ once every 3 weeks for 9 weeks delayed palatal wound healing [24]. Thus, in the present study, subcutaneous injection of the developed $\mathrm{mAb}$ at $5 \mathrm{mg} / \mathrm{kg}$ was performed once every 3 weeks because this regimen is comparable to denosumab treatment in humans. The estimated dosage of $\mathrm{mAb}$ for mice ranges from approximately 2 to $20 \mathrm{mg} / \mathrm{kg}$ based on translating the human clinical dose to mice [37], indicating that $5 \mathrm{mg} / \mathrm{kg}$ of $\mathrm{mAb}$ was the appropriate dose for mice in the present study.

Clinically, ZA is administered intravenously in humans. It has been reported that both subcutaneous 0.02 and $0.1 \mathrm{mg} / \mathrm{kg}$ administration of ZA (4 injections per each dosage) significantly increased the survival rate with preservation of long bone structures in bone metastasis model mice [38]. Single injection of $4 \mathrm{mg}$ of ZA in clinical use is equivalent to the cumulative dose ranging from about 0.08 to $0.8 \mathrm{mg} / \mathrm{kg}$ in mice $[37,38]$. Moreover, our previous studies already demonstrated that subcutaneous $0.05 \mathrm{mg} / \mathrm{kg}$ of ZA administration in combination with CY caused a high prevalence of BRONJ-like lesions in mice [9,25,32]. Therefore, based on these rationales for ZA administration, $0.05 \mathrm{mg} / \mathrm{kg}$ injection of ZA was selected in the present study, since the cumulative dose was 0.5 and $0.7 \mathrm{mg} / \mathrm{kg}$ until euthanasia at 2 and 4 weeks after tooth extraction, respectively.

On the other hand, CY is often injected intraperitoneally every day in cancer patients, reaching 3000 to $8000 \mathrm{mg}$ as the cumulative dose for one month in clinical situations. The estimated dosage of $\mathrm{CY}$ for mice ranges from approximately 20 to $55 \mathrm{mg} / \mathrm{kg}$ [37], for a cumulative dose for one month from 600 to $1600 \mathrm{mg}$ in mice. Therefore, intraperitoneal $\mathrm{CY}$ at $150 \mathrm{mg} / \mathrm{kg}$ was chosen not to exceed the appropriate cumulative dose until euthanasia, although this dosage is higher as a single injection. Moreover, as mentioned above, a high prevalence of BRONJ-like lesions has been demonstrated to be successfully created when CY at $150 \mathrm{mg} / \mathrm{kg}$ was intraperitoneally administered with ZA [9,25,32]. Thus, it was found that the effects of ZA and CY/ZA for 5 and 7 weeks on BV/TV and BMD of long bones were histologically and structurally similar to those of $\mathrm{mAb}$ and $\mathrm{CY} / \mathrm{mAb}$ for 4 weeks, respectively (data not shown).

Several studies have reported the development of ONJ-like lesions using RANK-Fc, OPG-Fc and anti-RANKL monoclonal antibodies [11-14]. However, all of these studies used antibody monotherapies to create RANKL-related ONJ-like lesions in rodents, although DRONJ rarely occurs in osteoporosis patients using denosumab monotherapy, but it occurs commonly in cancer patients receiving denosumab/chemotherapy combination therapy $[15,16]$. Thus, from this clinical viewpoint, high-dose antiresorptive/CY combination therapies were selected in the present study to mimic the clinical conditions at high risk for DRONJ.

In the present study, at 2 and 4 weeks post-extraction, gross, structural, and histopathological parameters were generally similar between the $\mathrm{CY} / \mathrm{mAb}$ and CY/ZA groups. Clinically, osteosclerosis occurs in the lamina dura, alveolar bone, and jawbone from the early stages of BRONJ and DRONJ [15,16,39]. Therefore, BMD may be increased due to bone sclerosis in the early stages of mAb-ONJ- and BRONJ-like lesions, although both $\mathrm{CY} / \mathrm{mAb}$ and $\mathrm{CY} / \mathrm{ZA}$ combination 


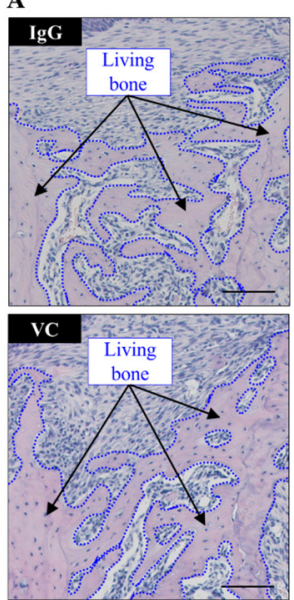

D

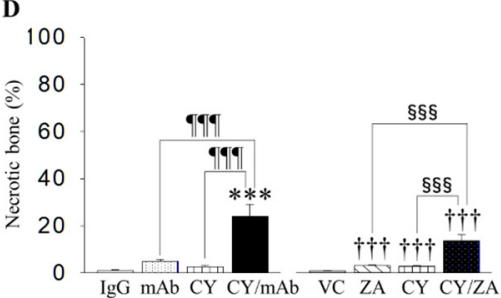

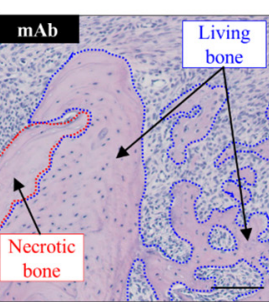

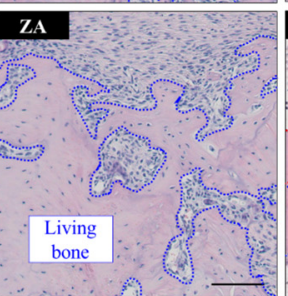

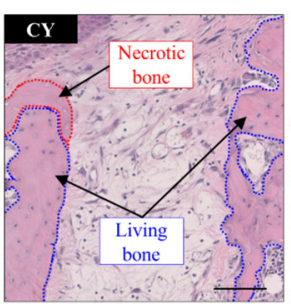

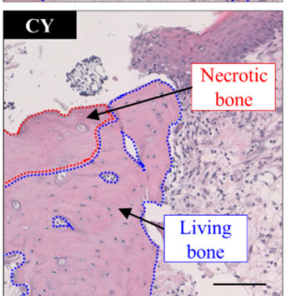

E

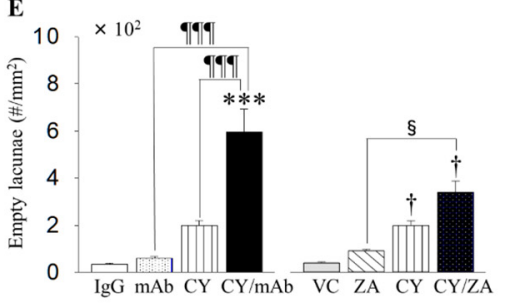

B

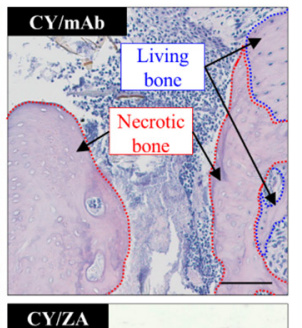

CY/ZA

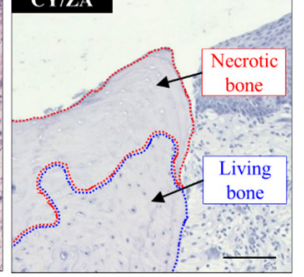

C
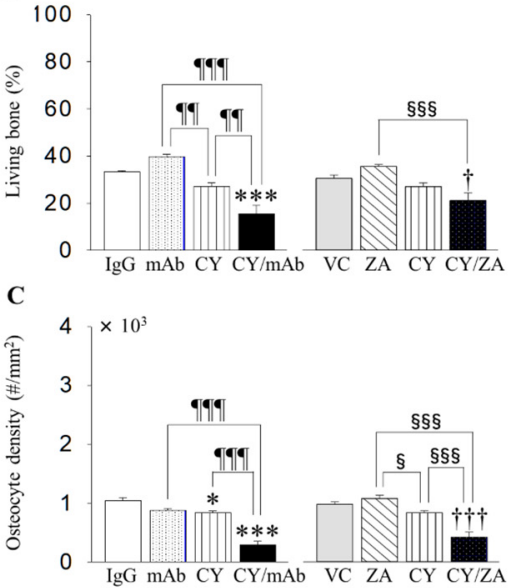

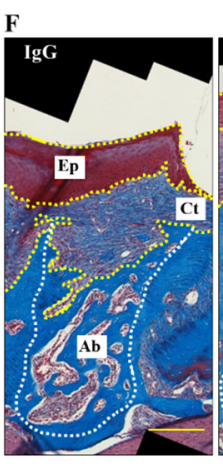

G

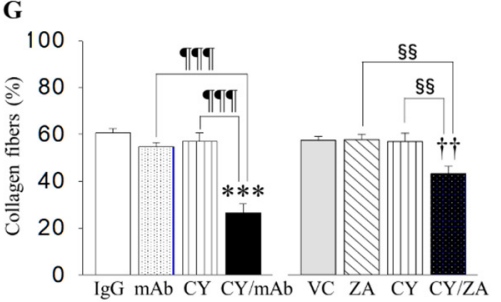

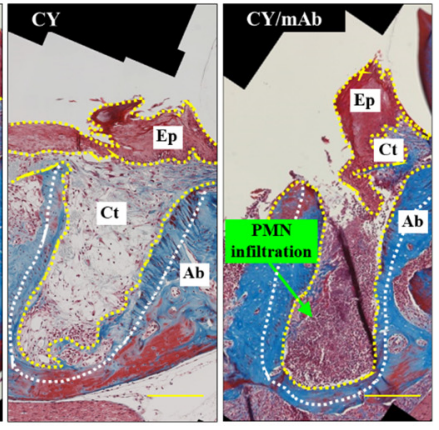
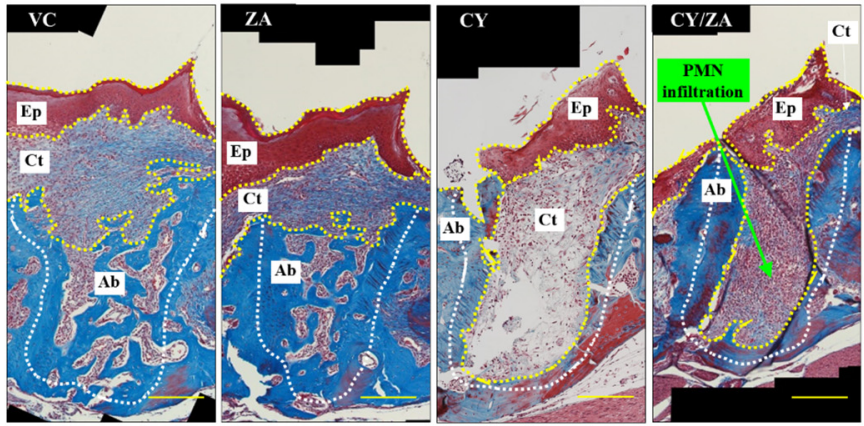

H

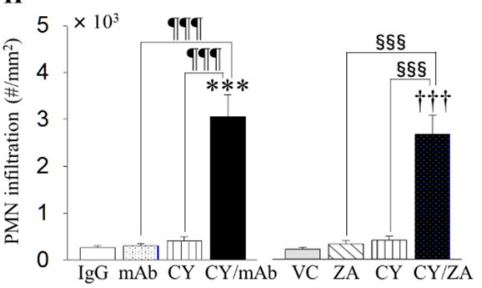

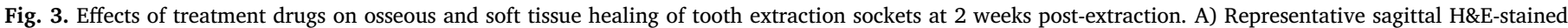

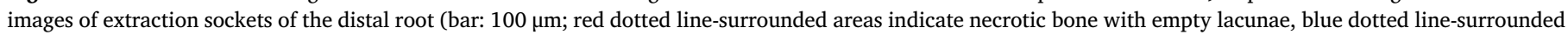

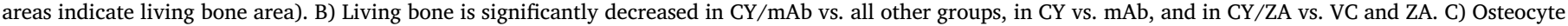

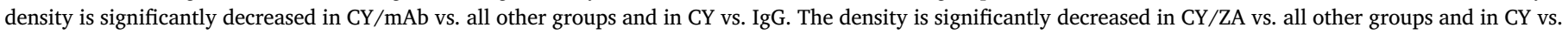

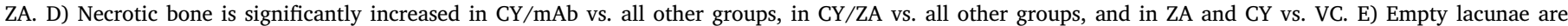

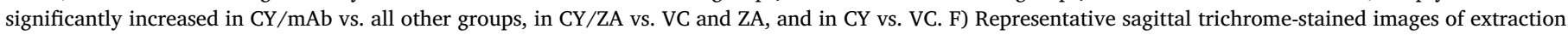

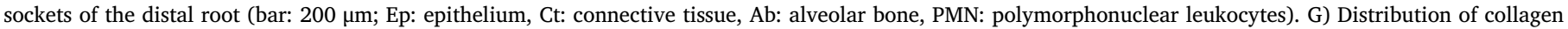

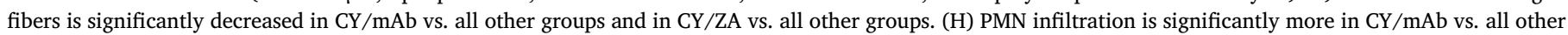

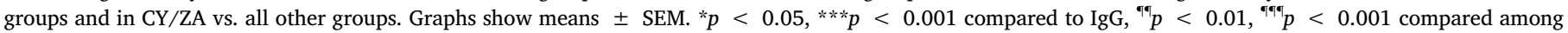

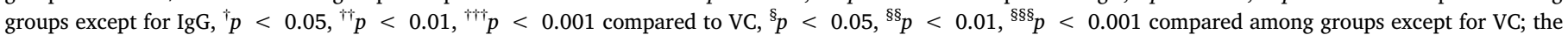
same data on CY were used in the comparison of IgG, mAb and CY/mAb, and VC, ZA and ZA/CY; $\mathrm{n}=7 \mathrm{mice} / \mathrm{group}$.

therapies worsened other evaluation parameters on $\mu \mathrm{CT}$ analyses. However, caution should be taken when interpreting the present result, since our previous data showed that BMD in CY/ZA combination therapy group was similar or significantly decreased compared with in VC [25,32].

In contrast, immunopathological parameters were quite different between the two types of impaired socket healing at 2 weeks after tooth extraction. We initially investigated angiogenesis and VEGFA distribution. VEGFA has been demonstrated to be requisite for normal formation of blood vessels [40]. In the present study, ZA monotherapy did not induce anti-angiogenesis with normal wound healing, whereas CY/ZA combination therapy reduced the number of blood vessels and VEGFA 

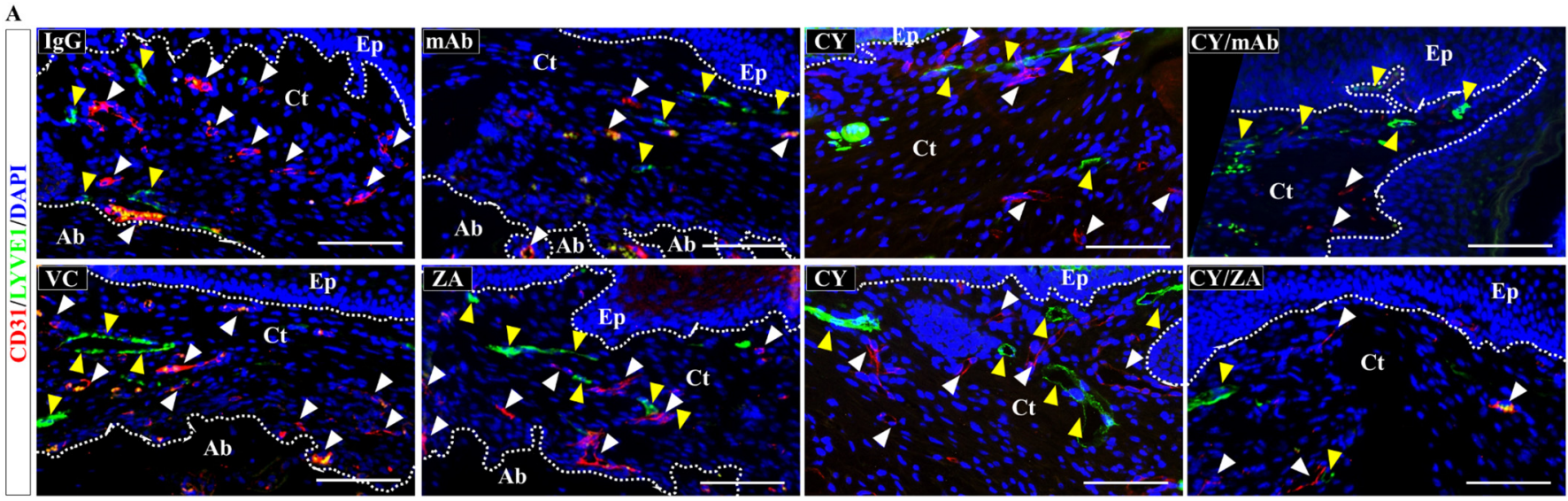
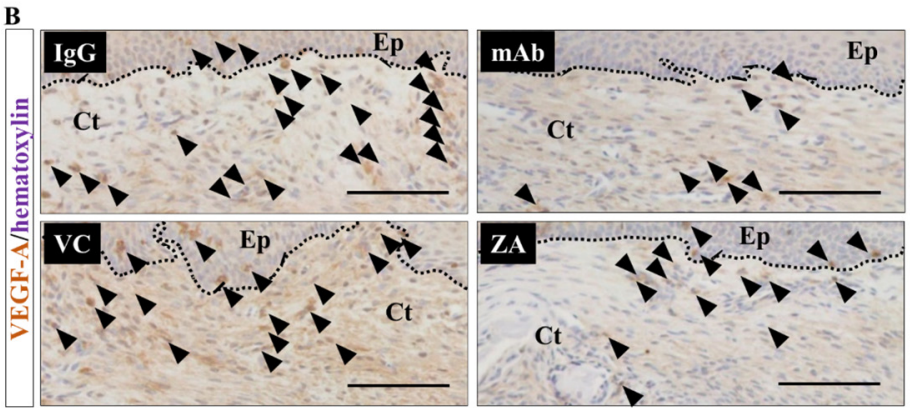

D
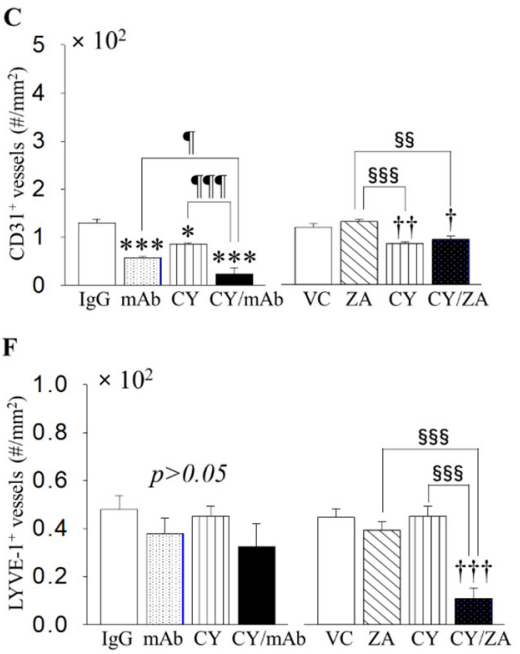
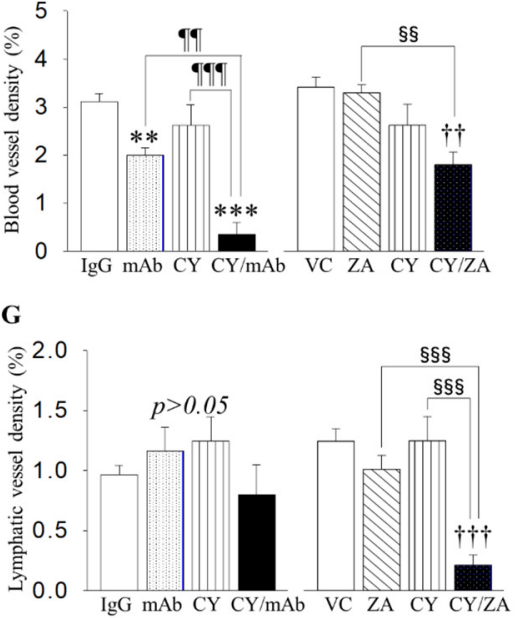

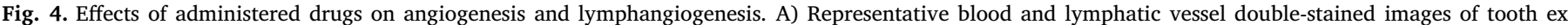

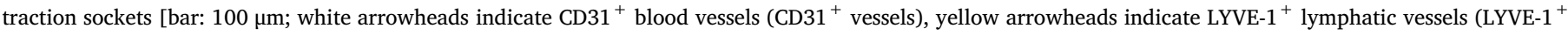

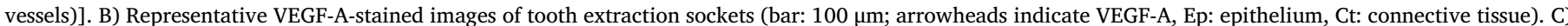

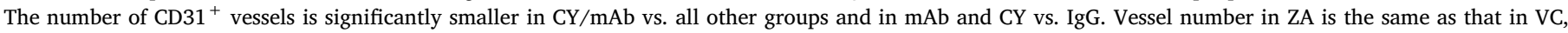

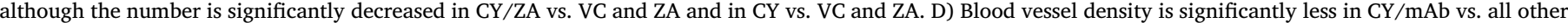

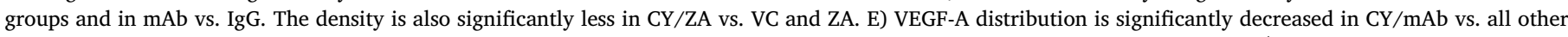

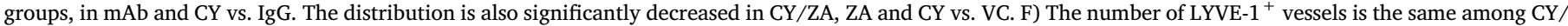

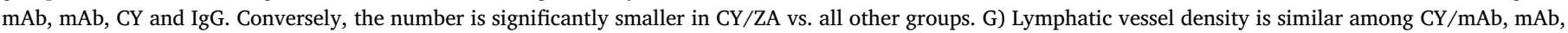

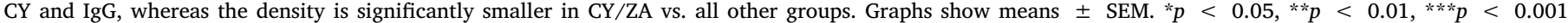

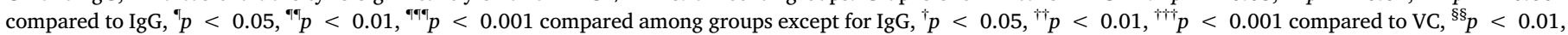

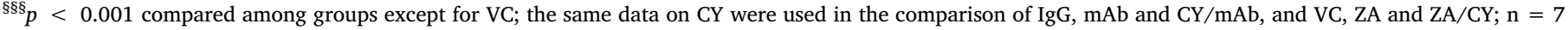
mice/group.

distribution in impaired socket wounds. CY monotherapy decreased the number of blood vessels and VEGFA, though with normal collagen production and a small amount of PMN infiltration. These findings were consistent with those of previous studies showing that CY monotherapy blocks angiogenesis both in vivo and in vitro [32,41], which suggests that ZA does not have an anti-angiogenic effect on soft tissue oral wounds under the present experimental conditions. Whether formation of blood vessels is a critical factor for developing BRONJ remains controversial. Some clinical studies have reported normal and/or increased angiogenesis in BRONJ patients [42,43]. On the other hand, ONJ occurs in patients receiving the anti-angiogenic agent bevacizumab. However, patients receiving anti-angiogenic inhibitors have other risk factors, such as combination therapy with chemotherapy, steroids, bisphosphonates and/or other drugs and abnormal immune 


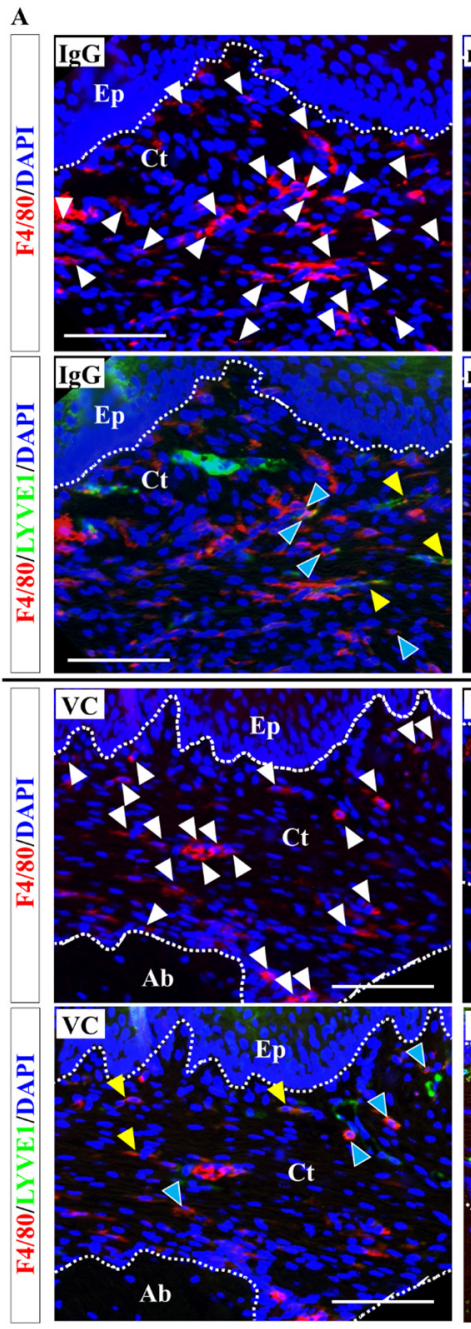

B

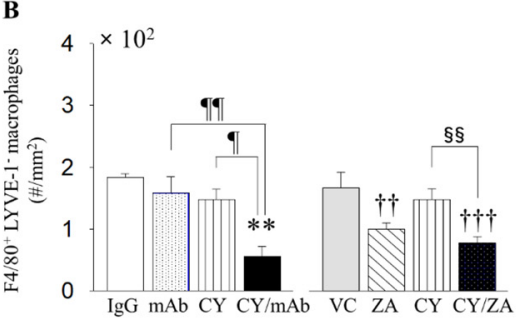

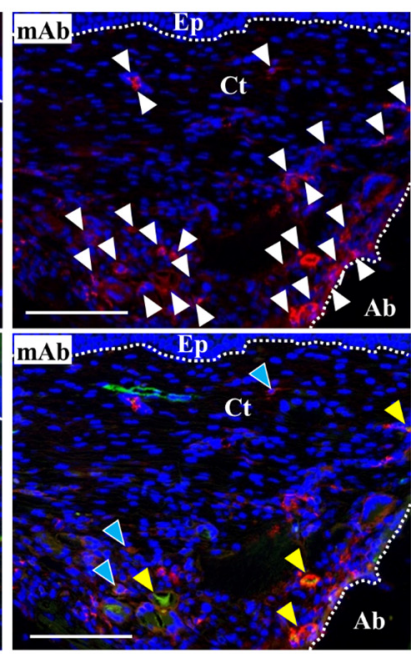
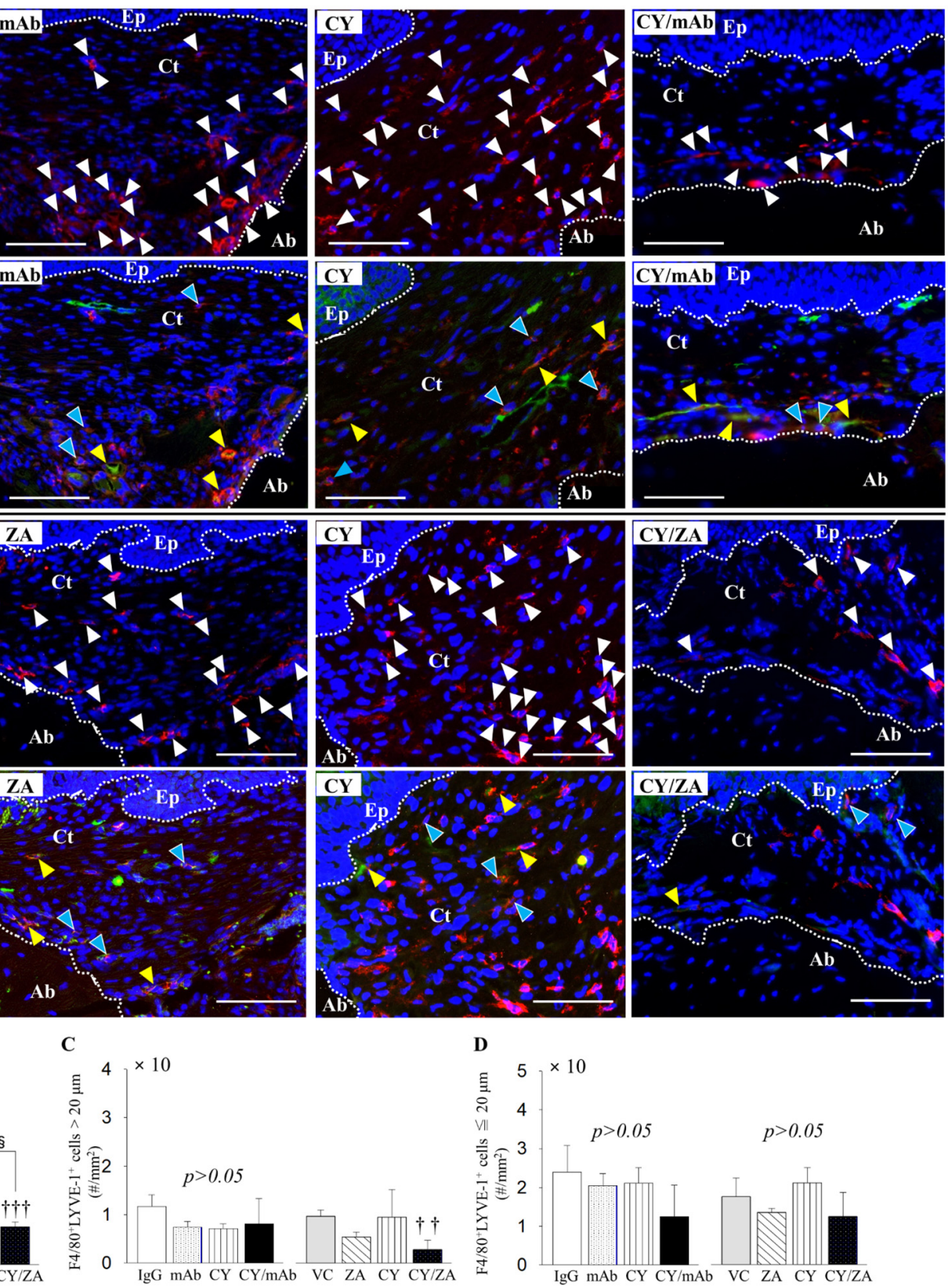

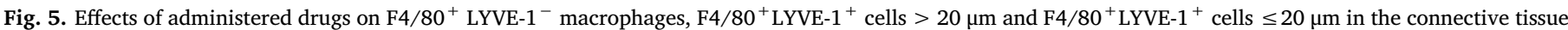

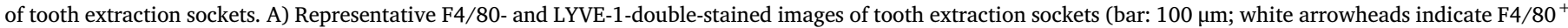

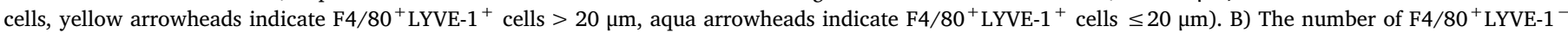

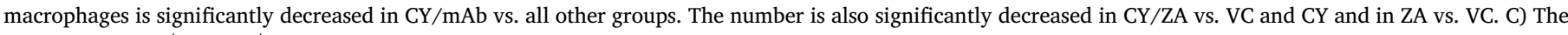

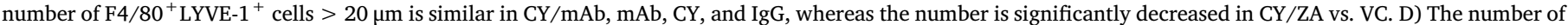

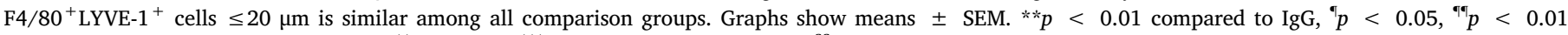

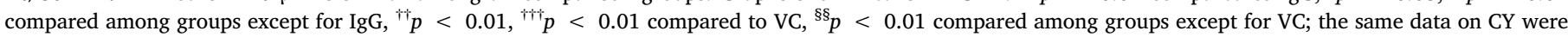
used in the comparison of $\mathrm{IgG}, \mathrm{mAb}$ and $\mathrm{CY} / \mathrm{mAb}$, and VC, ZA and ZA/CY; $\mathrm{n}=7$ mice/group.

systems [44]. Our recent study demonstrated that anti-angiogenesis induced by CY monotherapy did not induce impaired wound healing of tooth extraction sockets, although osseous healing of tooth extraction sockets was delayed [32]. Therefore, anti-angiogenesis alone does not induce BRONJ, although anti-angiogenesis may contribute partially to the development of BRONJ, suggesting that other key factors may play an important role in developing BRONJ.

There is limited information about angiogenesis in DRONJ [16]. Interestingly, $\mathrm{mAb}$ administration inhibited angiogenesis in the connective tissue of tooth extraction sockets, regardless of $\mathrm{CY}$ administration. A recent clinical study reported that denosumab significantly reduced angiogenesis in giant cell tumor of bone [45]. Furthermore, the interaction between RANKL and RANK expressed on vascular endothelial cells has been shown to improve cell proliferation, migration, and tube formation in vitro [46]. The same authors also showed that RANKL activates angiogenesis via a TRAF6-PIK3-Akt-dependent mechanism [47], lending credence to our findings. However, there is a conflicting report that denosumab did not affect vascular endothelial cell growth and tube formation in vitro [48]. Hence, caution should be exercised to determine whether $\mathrm{mAb}$ has an anti-angiogenic ability for oral wounds. Administration duration and route, experimental species (mice vs. humans), analyzed sites (normal vs. inflammation or tumor 
A

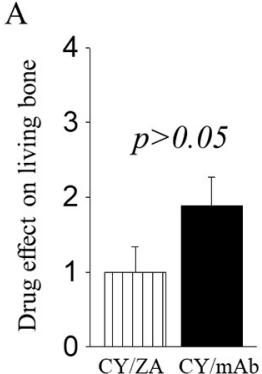

G

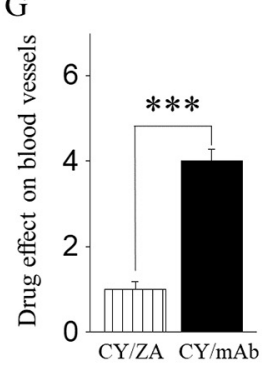

L

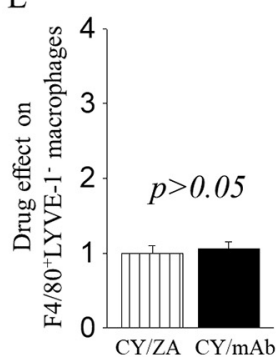

B

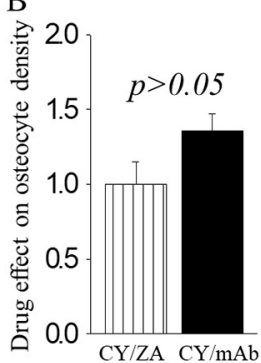

$\mathrm{H}$

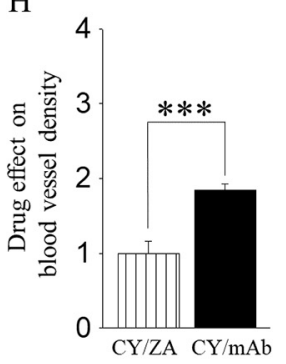

C

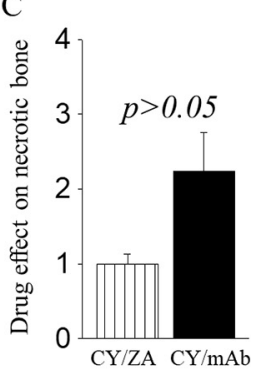

I

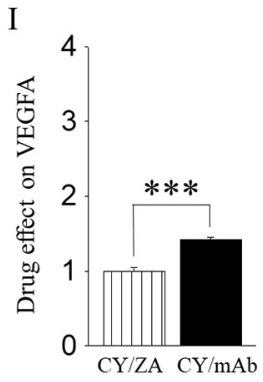

D

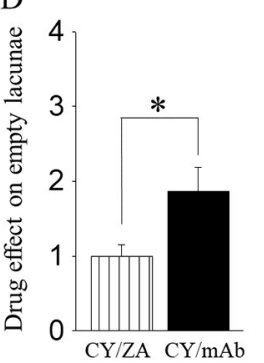

J

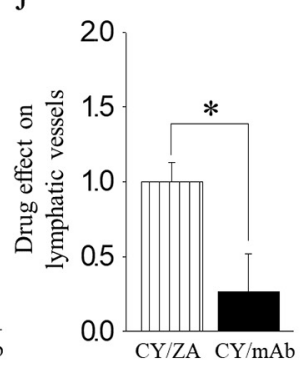

E

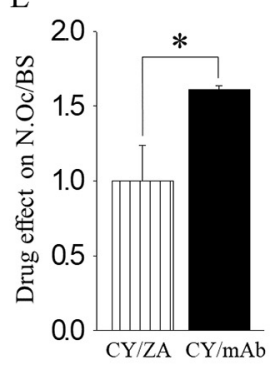

$\mathrm{F}$

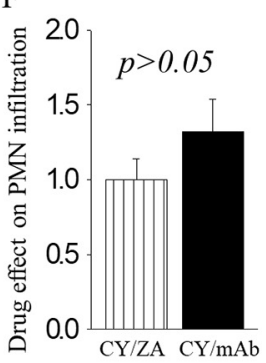

K

M

$\mathrm{N}$
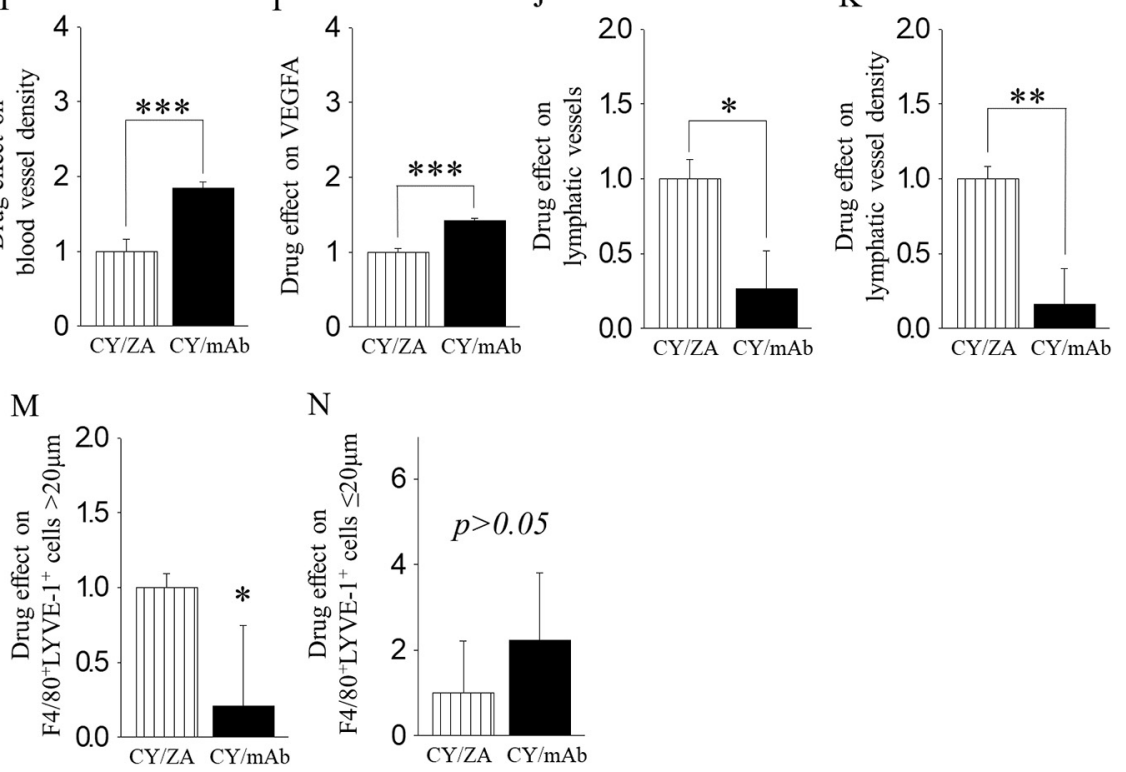

Fig. 6. Effects of $\mathrm{CY} / \mathrm{ZA}$ and $\mathrm{CY} / \mathrm{mAb}$ on each assessment parameter at 2 weeks post-extraction. A-C) Effects of administered drugs on living bone, osteocyte density, and necrotic bone are similar between CY/ZA and CY/mAb. D-E) Drug effects on empty lacunae and N.Oc/BS are significantly greater in CY/mAb than in CY/ZA. F) Drug effects on PMN infiltration are the same in the two groups. G-I) Drug effects on blood vessels, blood vessel density and VEGFA are significantly greater in CY/ $\mathrm{mAb}$ than in CY/ZA. J-K) Drug effects on lymphatic vessels and lymphatic vessel density are significantly smaller in CY/mAb vs. CY/ZA. L). Drug effects on F4/ $80^{+} \mathrm{LYVE}-1^{-}$macrophages are similar between CY/ZA and CY/mAb. M-N) Drug effects on F4/80 ${ }^{+} \mathrm{LYVE}-1^{+}$cells $\leq 20 \mu \mathrm{m}$ are similar between CY/mAb and CY/ZA, although the effect on F4/80 ${ }^{+}$LYVE $1^{+}$cells $>20 \mu \mathrm{m}$ is significantly greater in CY/ZA vs. CY/mAb. Graphs show means \pm SEM. ${ }^{*} p<0.05$, ${ }^{* *} p<0.01$, $* * * *<0.001$.

site and oral vs. other tissues), administered drugs (denosumab vs. antiRANKL neutralizing antibody), and the timing of analysis may affect angiogenesis in the connective tissue of tooth extraction sockets. However, in the present study, only $\mathrm{CY} / \mathrm{mAb}$ induced mAb-ONJ-like lesions, although both $\mathrm{mAb}$ and $\mathrm{CY}$ monotherapies reduced angiogenesis. Greater anti-angiogenesis and VEGFA production were evident in $\mathrm{CY} / \mathrm{mAb}$ compared with those in $\mathrm{CY} / \mathrm{ZA}$, due to synergistic and/or additive effects of $\mathrm{mAb}$ and $\mathrm{CY}$. Therefore, anti-angiogenesis may contribute to developing mAb-ONJ-like lesions rather than BRONJ-like lesions although a sole anti-angiogenesis dose not induce mAb-ONJ-like lesions as with BRONJ-like lesions.

It has been demonstrated that stabilin $-1^{+} \mathrm{F} 4 / 80^{+} \mathrm{CD} 11 \mathrm{~b}^{+}$macrophages express LYVE-1 in excisional skin and muscular wounds of abdominal regions in vivo, and bone marrow-derived macrophages express LYVE-1 in vitro [19]. LYVE-1 is known to be a specific marker of lymphatic endothelial cells [49]. Moreover, bone marrow-derived CD11 $b^{+}$LYVE- $^{+}$macrophages trans-differentiate into lymphatic endothelial cells that contain the capability of forming tube-like structures under inflamed conditions in vivo (cornea) and in vitro [20]. In our previous study, combination therapy involving the chemotherapy drug melphalan and ZA significantly reduced $\mathrm{F} 4 / 80^{+}$macrophages in BRONJ-like lesions in mice [17]. Therefore, finally, F4/80 ${ }^{+}$LYVE- $^{-}$ macrophages and F4/80 ${ }^{+}$LYVE- $^{+}$cells in the connective tissue of tooth extraction sockets were investigated to clarify whether they are associated with lymphangiogenesis. It has been reported that the diameter of mouse alveolar macrophages is approximately $20 \mu \mathrm{m}$, smaller than human macrophages [50]. According to this previous study and morphology from immune-stained images, $\mathrm{F} 4 / 80^{+}$cells were divided into F4 $/ 80^{+}$LYVE- $1^{-}$cells equivalent to macrophages, F4/80 ${ }^{+}$LYVE$1^{+}$cells $>20 \mu \mathrm{m}$ (like tube structures), and F4/80 ${ }^{+} \mathrm{LYVE}-1^{+}$cells $\leq 20 \mu \mathrm{m}$ (similar to $\mathrm{F} 4 / 80^{+}$macrophages) in the present study.

In the present study, severe PMN infiltration was observed in both antiresorptive/chemotherapeutic combination therapy-induced compromised oral wounds. Thus, both tooth extraction sockets should be inflamed. However, most interestingly, $\mathrm{CY} / \mathrm{mAb}$ rarely affected $\mathrm{F} 4$ / $80^{+}$LYVE- $^{+}$cells in impaired socket lesions and normal lymphangiogenesis remained, although $\mathrm{CY} / \mathrm{ZA}$ combination therapy significantly reduced the number of $\mathrm{F} 4 / 80^{+} \mathrm{LYVE}-1^{+}$cells $>20 \mu \mathrm{m}$ in impaired socket lesions with suppressed lymphangiogenesis. Therefore, the present findings suggest that $\mathrm{CY} / \mathrm{mAb}$, but not $\mathrm{CY} / \mathrm{ZA}$ may not inhibit F4 $/ 80^{+}$LYVE- $^{+}$cells from migrating into oral wounds from bone marrow and/or transdifferentiating into lymphatic endothelial cells or may not decrease the number of $\mathrm{F} 4 / 80^{+} \mathrm{LYVE}-1^{+}$cells in bone marrow, irrespective of cell size. Overall, the present immunopathological findings suggest that other key factors such as severe anti-angiogenesis but not $\mathrm{F} 4 / 80^{+} \mathrm{LYVE}^{+}{ }^{+}$cells and lymphangiogenesis may be important for the development of mAb-ONJ-like lesions, since drug effects on angiogenesis and VEGFA production were significantly greater in 
$\mathrm{CY} / \mathrm{mAb}$ combination therapy than in $\mathrm{CY} / \mathrm{ZA}$ combination therapy. On the other hand, the reduced number of F4/80 $0^{+} \mathrm{LYVE}-1^{+}$cells $>20 \mu \mathrm{m}$ with abnormal lymphangiogenesis may contribute to the onset of BRONJ-like lesions due to the negative drug effects on $\mathrm{F} 4 / 80^{+} \mathrm{LYVE}-1^{+}$ cells $>20 \mu \mathrm{m}$ and lymphangiogenesis in CY/ZA combination therapy when compared with those in $\mathrm{CY} / \mathrm{mAb}$ combination therapy. CY monotherapy also did not inhibit lymphangiogenesis under the present experimental conditions.

Therefore, the present data strongly indicates that the distribution patterns of $\mathrm{F} 4 / 80^{+} \mathrm{LYVE}^{+}{ }^{+}$cells $>20 \mu \mathrm{m}$ in conjunction with lymphangiogenesis are distinctly different in the early stages between BRONJ-like and mAb-ONJ-like lesions, although histopathologic patterns such as decreased living bone, reduced number of normal osteocytes, greater amount of necrotic bone and heavy PMN infiltration were the same between the two types of ONJ-like lesions.

\section{Conclusions}

In summary, within the limitations of this study due to higher doses of administered drugs and insufficient mimicry of clinical situations with non-cancer mice, high-prevalence ONJ-like lesions induced by anti-RANKL antibody/chemotherapeutic combination therapy were first developed taking into account ONJ prevalence, triggering factors for DRONJ, the population, and combined drug therapy. It was demonstrated that immunopathological conditions were clearly different in the early stages between distinct antiresorptive-related ONJ-like lesions, since $\mathrm{CY} / \mathrm{mAb}$ combination therapy rarely affected the larger size of $\mathrm{F} 4 / 80^{+} \mathrm{LYVE}^{+} \mathrm{1}^{+}$tube-like-structured cells and lymphangiogenesis, whereas CY/ZA combination therapy severely suppressed both of them. Moreover, $\mathrm{mAb}$ monotherapy was found to inhibit angiogenesis in the soft tissue of tooth extraction sockets, leading to greater anti-angiogenesis in $\mathrm{CY} / \mathrm{mAb}$ combination therapy. The generated mouse model will aid in developing therapeutic strategies and further elucidating the exact pathogenesis of BRONJ/DRONJ.

Supplementary data to this article can be found online at https:// doi.org/10.1016/j.bone.2020.115308.

\section{CRediT authorship contribution statement}

Hiroki Hayano: Investigation, Data curation, Validation, Visualization, Writing - original draft, Writing - review \& editing, Methodology, Software. Shinichiro Kuroshima: Project administration, Funding acquisition, Conceptualization, Investigation, Data curation, Methodology, Writing - original draft, Writing - review \& editing, Supervision. Muneteru Sasaki: Visualization, Software, Validation. Saki Tamaki: Investigation, Data curation. Maaya Inoue: Software, Validation. Akira Ishisaki: Funding acquisition, Writing original draft, Writing - review \& editing. Takashi Sawase: Writing original draft, Writing - review \& editing, Supervision.

\section{Acknowledgements}

This work was supported by grant support from JSPS KAKENHI [Grant Nos 18H02994 (SK) and 16H05534 (AI)]. All authors declare no potential conflicts of interest with respect to the authorship and/or publication of this article.

\section{Declaration of competing interest}

The authors declare that they have no conflicts of interest.

\section{References}

1] D.H. Henry, L. Costa, F. Goldwasser, V. Hirsh, V. Hungria, J. Prausova, G.V. Scagliotti, H. Sleeboom, A. Spencer, S. Vadhan-Raj, R. von Moos, W. Willenbacher, P.J. Woll, J. Wang, Q. Jiang, S. Jun, R. Dansey, H. Yeh,
Randomized, double-blind study of denosumab versus zoledronic acid in the treatment of bone metastases in patients with advanced cancer (excluding breast and prostate cancer) or multiple myeloma, J. Clin. Oncol. 29 (2011) 1125-1132, https://doi.org/10.1200/JCO.2010.31.3304.

[2] K. Fizazi, M. Carducci, M. Smith, R. Damião, J. Brown, L. Karsh, P. Milecki, N. Shore, M. Rader, H. Wang, Q. Jiang, S. Tadros, R. Dansey, C. Goessl, Denosumab versus zoledronic acid for treatment of bone metastases in men with castrationresistant prostate cancer: a randomised, double-blind study, Lancet 377 (2011) 813-822, https://doi.org/10.1016/S0140-6736(10)62344-6.

[3] A.T. Stopeck, A. Lipton, J.J. Body, G.G. Steger, K. Tonkin, R.H. de Boer, M. Lichinitser, Y. Fujiwara, D.A. Yardley, M. Viniegra, M. Fan, Q. Jiang, R. Dansey, S. Jun, A. Braun, Denosumab compared with zoledronic acid for the treatment of bone metastases in patients with advanced breast cancer: a randomized, doubleblind study, J. Clin. Oncol. 28 (2010) 5132-5139, https://doi.org/10.1200/JCO. 2010.29.7101.

[4] C. Campbell-Baird, S. Harrelson, G. Frey, A. Balakumaran, Clinical efficacy of denosumab versus bisphosphonates for the prevention of bone complications: implications for nursing, Support Care Cancer 23 (2015) 3625-3632, https://doi.org/ 10.1007/s00520-015-2887-2.

[5] T.L. Aghaloo, A.L. Felsenfeld, S. Tetradis, Osteonecrosis of the jaw in a patient on denosumab, J. Oral Maxillofac. Surg. 68 (2010) 959-963, https://doi.org/10.1016/ j.joms.2009.10.010.

[6] R.E. Marx, Pamidronate (Aredia) and zoledronate (Zometa) induced avascular necrosis of the jaws: a growing epidemic, J. Oral Maxillofac. Surg. 61 (2003) 1115-1117, https://doi.org/10.1016/s0278-2391(03)00720-1.

[7] D.B. Kimmel, Mechanism of action, pharmacokinetic and pharmacodynamic profile, and clinical applications of nitrogen-containing bisphosphonates, J. Dent. Res. 86 (2007) 1022-1033, https://doi.org/10.1177/154405910708601102.

[8] R. Baron, S. Ferrari, R.G. Russell, Denosumab and bisphosphonates: different mechanisms of action and effects, Bone 48 (2011) 677-692, https://doi.org/10.1016/ j.bone.2010.11.020

[9] S. Kuroshima, M. Sasaki, K. Nakajima, S. Tamaki, H. Hayano, T. Sawase, Transplantation of noncultured stromal vascular fraction cells of adipose tissue ameliorates osteonecrosis of the jaw-like lesions in mice, J. Bone Miner. Res. 33 (2018) 154-166, https://doi.org/10.1002/jbmr.3292.

[10] R. Fliefel, M. Tröltzsch, J. Kühnisch, M. Ehrenfeld, S. Otto, Treatment strategies and outcomes of bisphosphonate-related osteonecrosis of the jaw (BRONJ) with characterization of patients: a systematic review, Int. J. Oral Maxillofac. Surg. 44 (2015) 568-585, https://doi.org/10.1016/j.ijom.2015.01.026.

[11] R.S. de Molon, H. Shimamoto, O. Bezouglaia, F.Q. Pirih, S.M. Dry, P. Kostenuik, R.W. Boyce, D. Dwyer, T.L. Aghaloo, S. Tetradis, OPG-Fc but not zoledronic acid discontinuation reverses osteonecrosis of the jaws (ONJ) in mice, J. Bone Miner. Res. 30 (2015) 1627-1640, https://doi.org/10.1002/jbmr.2490.

[12] A. Soundia, D. Hadaya, N. Esfandi, R.S. de Molon, O. Bezouglaia, S.M. Dry, F.Q. Pirih, T. Aghaloo, S. Tetradis, Osteonecrosis of the jaws (ONJ) in mice after extraction of teeth with periradicular disease, Bone 90 (2016) 133-141, https://doi. org/10.1016/j.bone.2016.06.011.

[13] T.L. Aghaloo, S. Cheong, O. Bezouglaia, P. Kostenuik, E. Atti, S.M. Dry, F.Q. Pirih, S. Tetradis, RANKL inhibitors induce osteonecrosis of the jaw in mice with periapical disease, J. Bone Miner. Res. 29 (2014) 843-854, https://doi.org/10.1002/ jbmr.2097.

[14] D.W. Williams, C. Lee, T. Kim, H. Yagita, H. Wu, S. Park, P. Yang, H. Liu, S. Shi, K.H. Shin, M.K. Kang, N.H. Park, R.H. Kim, Impaired bone resorption and woven bone formation are associated with development of osteonecrosis of the jaw-like lesions by bisphosphonate and anti-receptor activator of NF-kB ligand antibody in mice, Am. J. Pathol. 184 (2014) 3084-3093, https://doi.org/10.1016/j.ajpath. 2014.07.010.

[15] S.L. Ruggiero, T.B. Dodson, J. Fantasia, R. Goodday, T. Aghaloo, B. Mehrotra, F. O'Ryan, American Association of Oral and Maxillofacial Surgeons, American Association of Oral and Maxillofacial Surgeons position paper on medication-related osteonecrosis of the jaw-2014 update, J. Oral Maxillofac. Surg. 72 (2014) 1938-1956, https://doi.org/10.1016/j.joms.2014.04.031.

[16] A.A. Khan, A. Morrison, D.A. Hanley, D. Felsenberg, L.K. McCauley, F. O'Ryan, I.R. Reid, S.L. Ruggiero, A. Taguchi, S. Tetradis, N.B. Watts, M.L. Brandi, E. Peters, T. Guise, R. Eastell, A.M. Cheung, S.N. Morin, B. Masri, C. Cooper, S.L. Morgan, B. Obermayer-Pietsch, B.L. Langdahl, R. Al Dabagh, K.S. Davison, D.L. Kendler, G.K. Sándor, R.G. Josse, M. Bhandari, M. El Rabbany, D.D. Pierroz, R. Sulimani, D.P. Saunders, J.P. Brown, J. Compston, Internatinal Task Force on Osteonecrosis of the Jaw, Diagnosis and management of osteonecrosis of the jaw: a systematic review and international consensus, J. Bone Miner. Res. 30 (2015) 3-23, https://doi. org/10.1002/jbmr.2405.

[17] S. Kuroshima, J. Yamashita, Chemotherapeutic and antiresorptive combination therapy suppressed lymphangiogenesis and induced osteonecrosis of the jaw-like lesions in mice, Bone 56 (2013) 101-109, https://doi.org/10.1016/j.bone.2013.05. 013.

[18] Q. Zhang, I. Atsuta, S. Liu, C. Chen, S. Shi, A.D. Le, IL-17-mediated M1/M2 macrophage alteration contributes to pathogenesis of bisphosphonate-related osteonecrosis of the jaws, Clin. Cancer Res. 19 (2013) 3176-3188, https://doi.org/10. 1158/1078-0432.CCR-13-0042.

[19] K. Schledzewski, M. Falkowski, G. Moldenhauer, P. Metharom, J. Kzhyshkowska, R. Ganss, A. Demory, B. Falkowska-Hansen, H. Kurzen, S. Ugurel, G. Geginat, B. Arnold, S. Goerdt, Lymphatic endothelium-specific hyaluronan receptor LYVE-1 is expressed by stabilin- $1+, \mathrm{F} 4 / 80+, \mathrm{CD} 11 \mathrm{~b}+$ macrophages in malignant tumours and wound healing tissue in vivo and in bone marrow cultures in vitro: implications for the assessment of lymphangiogenesis, J. Pathol. 209 (2006) 67-77, https://doi. org/10.1002/path.1942. 
[20] K. Maruyama, M. Ii, C. Cursiefen, D.G. Jackson, H. Keino, M. Tomita, N. Van Rooijen, H. Takenaka, P.A. D'Amore, J. Stein-Streilein, D.W. Losordo, J.W. Streilein, Inflammation-induced lymphangiogenesis in the cornea arises from CD11b-positive macrophages, J. Clin. Invest. 115 (2005) 2363-2372, https://doi.org/10.1172/ JCI23874.

[21] D. Ribatti, E. Crivellato, Immune cells and angiogenesis, J. Cell Mol. Med. 13 (2009) 2822-2833, https://doi.org/10.1111/j.1582-4934.2009.00810.x.

[22] A.M. Platt, J.M. Rutkowski, C. Martel, E.L. Kuan, S. Ivanov, M.A. Swartz, G.J. Randolph, Normal dendritic cell mobilization to lymph nodes under conditions of severe lymphatic hypoplasia, J. Immunol. 190 (2013) 4608-4620, https://doi. org/10.4049/jimmunol.1202600.

[23] M. Dai, YY. Yip, I. Hellstrom, K.E. Hellstrom, Curing mice with large tumors by locally delivering combinations of immunomodulatory antibodies, Clin. Cancer Res. 21 (2015) 1127-1138, https://doi.org/10.1158/1078-0432.CCR-14-1339.

[24] S. Kuroshima, Z. Al-Salihi, J. Yamashita, Mouse anti-RANKL antibody delays oral wound healing and increases TRAP-positive mononuclear cells in bone marrow, Clin. Oral Investig. 20 (2016) 727-736, https://doi.org/10.1007/s00784-0151550-0.

[25] S. Kuroshima, M. Sasaki, K. Nakajima, S. Tamaki, H. Hayano, T. Sawase, Prevalence of bisphosphonate-related osteonecrosis of the jaw-like lesions is increased in a chemotherapeutic dose-dependent manner in mice, Bone 112 (2018) 177-186, https://doi.org/10.1016/j.bone.2018.05.001.

[26] M.L. Bouxsein, S.K. Boyd, B.A. Christiansen, R.E. Guldberg, K.J. Jepsen, R. Müller, Guidelines for assessment of bone microstructure in rodents using micro-computed tomography, J. Bone Miner. Res. 25 (2010) 1468-1486, https://doi.org/10.1002/ jbmr.141.

[27] A. Bedogni, S. Blandamura, Z. Lokmic, C. Palumbo, M. Ragazzo, F. Ferrari, A. Tregnaghi, F. Pietrogrande, O. Procopio, G. Saia, M. Ferretti, G. Bedogni, L. Chiarini, G. Ferronato, V. Ninfo, L. Lo Russo, L. Lo Muzio, P.F. Nocini, Bisphosphonate-associated jawbone osteonecrosis: a correlation between imaging techniques and histopathology, Oral Surg. Oral Med. Oral Pathol. Oral Radiol. Endod. 105 (2008) 358-364, https://doi.org/10.1016/j.tripleo.2007.08.040.

[28] C. Fondi, A. Franchi, Definition of bone necrosis by the pathologist, Clin. Cases Miner. Bone Metab, 4 (2007) 21-26.

[29] E. Franco-Pretto, M. Pacheco, A. Moreno, O. Messa, J. Gnecco, Bisphosphonateinduced osteonecrosis of the jaws: clinical, imaging, and histopathology findings, Oral Surg. Oral Med. Oral Pathol. Oral Radiol. 118 (2014) 408-417, https://doi. org/10.1016/j.oooo.2014.04.017.

[30] D. Carmagnola, E. Canciani, D. Sozzi, F. Biglioli, L. Moneghini, C. Dellavia, Histological findings on jaw osteonecrosis associated with bisphosphonates (BONJ) or with radiotherapy (ORN) in humans, Acta Odontol. Scand. 71 (2013) 1410-1417, https://doi.org/10.3109/00016357.2013.765592.

[31] A.E. Vieira, C.E. Repeke, S.e.B. Ferreira Junior, P.M. Colavite, C.C. Biguetti, R.C. Oliveira, G.F. Assis, R. Taga, A.P. Trombone, G.P. Garlet, Intramembranous bone healing process subsequent to tooth extraction in mice: micro-computed tomography, histomorphometric and molecular characterization, PLoS One 10 (2015) e0128021, https://doi.org/10.1371/journal.pone.0128021.

[32] Y. Akita, S. Kuroshima, K. Nakajima, H. Hayano, R. Kanai, M. Sasaki, T. Sawase, Effect of anti-angiogenesis induced by chemotherapeutic monotherapy, chemotherapeutic/bisphosphonate combination therapy and anti-VEGFA mAb therapy on tooth extraction socket healing in mice, J. Bone Miner. Metab. 36 (2018) 547-559, https://doi.org/10.1007/s00774-017-0872-1.

[33] Y. Kobayashi, T. Hiraga, A. Ueda, L. Wang, M. Matsumoto-Nakano, K. Hata, H. Yatani, T. Yoneda, Zoledronic acid delays wound healing of the tooth extraction socket, inhibits oral epithelial cell migration, and promotes proliferation and adhesion to hydroxyapatite of oral bacteria, without causing osteonecrosis of the jaw, in mice, J. Bone Miner. Metab. 28 (2010) 165-175, https://doi.org/10.1007/ s00774-009-0128-9.

[34] J. Yamashita, K. Koi, D.Y. Yang, L.K. McCauley, Effect of zoledronate on oral wound healing in rats, Clin. Cancer Res. 17 (2011) 1405-1414, https://doi.org/10.1158/ 1078-0432.CCR-10-1614.

[35] S. Park, A. Hokugo, S. Sun, C.E. McKenna, I. Nishimura, Equilibrium-dependent bisphosphonate interaction with crystalline bone mineral explains anti-resorptive pharmacokinetics and prevalence of osteonecrosis of the jaw in rats, Bone 53 (2013) 59-68, https://doi.org/10.1016/j.bone.2012.11.030.
[36] Y. Furuya, K. Mori, T. Ninomiya, Y. Tomimori, S. Tanaka, N. Takahashi, N. Udagawa, K. Uchida, H. Yasuda, Increased bone mass in mice after single injection of anti-receptor activator of nuclear factor-kappaB ligand-neutralizing antibody: evidence for bone anabolic effect of parathyroid hormone in mice with few osteoclasts, J. Biol. Chem. 286 (2011) 37023-37031, https://doi.org/10.1074/jbc. M111.246280.

[37] S. Reagan-Shaw, M. Nihal, N. Ahmad, Dose translation from animal to human studies revisited, FASEB J. 22 (2008) 659-661, https://doi.org/10.1096/fj.079574LSF.

[38] T.T. Hung, J. Chan, P.J. Russell, C.A. Power, Zoledronic acid preserves bone structure and increases survival but does not limit tumour incidence in a prostate cancer bone metastasis model, PLoS One 6 (2011) e19389, , https://doi.org/10. 1371/journal.pone.0019389.

[39] M. Hutchinson, F. O'Ryan, V. Chavez, P.V. Lathon, G. Sanchez, D.C. Hatcher, A.T. Indresano, J.C. Lo, Radiographic findings in bisphosphonate-treated patients with stage 0 disease in the absence of bone exposure, J. Oral Maxillofac. Surg. 68 (2010) 2232-2240, https://doi.org/10.1016/j.joms.2010.05.003.

[40] P. Carmeliet, V. Ferreira, G. Breier, S. Pollefeyt, L. Kieckens, M. Gertsenstein, M. Fahrig, A. Vandenhoeck, K. Harpal, C. Eberhardt, C. Declerca, J. Pawling, L. Moons, D. Collen, W. Risau, A. Nagy, Abnormal blood vessel development and lethality in embryos lacking a single VEGF allele, Nature 380 (1996) 435-439, https://doi.org/10.1038/380435a0.

[41] T. Browder, C.E. Butterfield, B.M. Kräling, B. Shi, B. Marshall, M.S. O'Reilly, J. Folkman, Antiangiogenic scheduling of chemotherapy improves efficacy against experimental drug-resistant cancer, Cancer Res. 60 (2000) 1878-1886.

[42] P. Lesclous, S. Abi Najm, J.P. Carrel, B. Baroukh, T. Lombardi, J.P. Willi, R. Rizzoli, J.L. Saffar, J. Samson, Bisphosphonate-associated osteonecrosis of the jaw: a key role of inflammation? Bone 45 (2009) 843-852, https://doi.org/10.1016/j.bone. 2009.07.011.

[43] T. Hansen, M. Kunkel, A. Weber, C. James Kirkpatrick, Osteonecrosis of the jaws in patients treated with bisphosphonates - histomorphologic analysis in comparison with infected osteoradionecrosis, J. Oral Pathol. Med. 35 (2006) 155-160, https:// doi.org/10.1111/j.1600-0714.2006.00391.x.

[44] V. Guarneri, D. Miles, N. Robert, V. Diéras, J. Glaspy, I. Smith, C. Thomssen, L. Biganzoli, T. Taran, P. Conte, Bevacizumab and osteonecrosis of the jaw: incidence and association with bisphosphonate therapy in three large prospective trials in advanced breast cancer, Breast Cancer Res. Treat. 122 (2010) 181-188, https://doi.org/10.1007/s10549-010-0866-3.

[45] I. Girolami, I. Mancini, A. Simoni, G.G. Baldi, L. Simi, D. Campanacci, G. Beltrami, G. Scoccianti, A. D'Arienzo, R. Capanna, A. Franchi, Denosumab treated giant cell tumour of bone: a morphological, immunohistochemical and molecular analysis of a series, J. Clin. Pathol. 69 (2016) 240-247, https://doi.org/10.1136/jclinpath2015-203248.

[46] Y.M. Kim, Y.M. Lee, H.S. Kim, J.D. Kim, Y. Choi, K.W. Kim, S.Y. Lee, Y.G. Kwon, TNF-related activation-induced cytokine (TRANCE) induces angiogenesis through the activation of Src and phospholipase C (PLC) in human endothelial cells, J. Biol. Chem. 277 (2002) 6799-6805, https://doi.org/10.1074/jbc.M109434200.

[47] J.K. Min, Y.M. Kim, E.C. Kim, Y.S. Gho, I.J. Kang, S.Y. Lee, Y.Y. Kong, Y.G. Kwon, Vascular endothelial growth factor up-regulates expression of receptor activator of NF-kappa B (RANK) in endothelial cells. Concomitant increase of angiogenic responses to RANK ligand, J. Biol. Chem. 278 (2003) 39548-39557, https://doi.org/ 10.1074/jbc.M300539200.

[48] J.K. Min, Y.L. Cho, J.H. Choi, Y. Kim, J.H. Kim, Y.S. Yu, J. Rho, N. Mochizuki, Y.M. Kim, G.T. Oh, Y.G. Kwon, Receptor activator of nuclear factor (NF)-kappaB ligand (RANKL) increases vascular permeability: impaired permeability and angiogenesis in eNOS-deficient mice, Blood 109 (2007) 1495-1502, https://doi.org/ 10.1182/blood-2006-06-029298.

[49] S. Banerji, J. Ni, S.X. Wang, S. Clasper, J. Su, R. Tammi, M. Jones, D.G. Jackson, LYVE-1, a new homologue of the CD44 glycoprotein, is a lymph-specific receptor for hyaluronan, J. Cell Biol. 144 (1999) 789-801, https://doi.org/10.1083/jcb.144. 4.789.

[50] P.J. Haley, B.A. Muggenburg, D.N. Weissman, D.E. Bice, Comparative morphology and morphometry of alveolar macrophages from six species, Am. J. Anat. 191 (1991) 401-407, https://doi.org/10.1002/aja.1001910407. 